\title{
Variations on a theme: diversification of cuticular hydrocarbons in a clade of cactophilic Drosophila
}

\author{
Cássia C de Oliveira ${ }^{1,2^{*}}$, Maura H Manfrin ${ }^{3}$, Fábio de M Sene ${ }^{4}$, Larry L Jackson ${ }^{5}$ and William J Etges ${ }^{1}$
}

\begin{abstract}
Background: We characterized variation and chemical composition of epicuticular hydrocarbons (CHCS) in the seven species of the Drosophila buzzatii cluster with gas chromatography/mass spectrometry. Despite the critical role of CHCs in providing resistance to desiccation and involvement in communication, such as courtship behavior, mating, and aggregation, few studies have investigated how CHC profiles evolve within and between species in a phylogenetic context. We analyzed quantitative differences in $\mathrm{CHC}$ profiles in populations of the D. buzzatii species cluster in order to assess the concordance of CHC differentiation with species divergence.
\end{abstract}

Results: Thirty-six $\mathrm{CHC}$ components were scored in single fly extracts with carbon chain lengths ranging from $\mathrm{C}_{29}$ to $C_{39}$, including methyl-branched alkanes, $n$-alkenes, and alkadienes. Multivariate analysis of variance revealed that $\mathrm{CHC}$ amounts were significantly different among all species and canonical discriminant function (CDF) analysis resolved all species into distinct, non-overlapping groups. Significant intraspecific variation was found in different populations of $D$. serido suggesting that this taxon is comprised of at least two species. We summarized CHC variation using CDF analysis and mapped the first five CHC canonical variates (CVs) onto an independently derived period (per) gene + chromosome inversion + mtDNA COI gene for each sex. We found that the COI sequences were not phylogenetically informative due to introgression between some species, so only per + inversion data were used. Positive phylogenetic signal was observed mainly for CV1 when parsimony methods and the test for serial independence (TFSI) were used. These results changed when no outgroup species were included in the analysis and phylogenetic signal was then observed for female CV3 and/or CV4 and male CV4 and CV5. Finally, removal of divergent populations of $D$. serido significantly increased the amount of phylogenetic signal as up to four out of five CVs then displayed positive phylogenetic signal.

Conclusions: CHCs were conserved among species while quantitative differences in CHC profiles between populations and species were statistically significant. Most CHCs were species-, population-, and sex-specific. Mapping CHCs onto an independently derived phylogeny revealed that a significant portion of $\mathrm{CHC}$ variation was explained by species' systematic affinities indicating phylogenetic conservatism in the evolution of these hydrocarbon arrays, presumptive waterproofing compounds and courtship signals as in many other drosophilid species.

\section{Background}

The nested hierarchical nature of species due to shared ancestry has been useful in comparative biology to assess relative rates of phenotypic evolution [1]. In a comprehensive comparative study, Blomberg et al. [2] showed that behavioral traits were more labile (weakly or uncorrelated with phylogeny) than body size, morphological,

\footnotetext{
* Correspondence: coliveira2@unl.edu

'Program in Ecology and Evolutionary Biology, Department of Biological Sciences, SCEN 632, University of Arkansas, Fayetteville, AR 72701, USA Full list of author information is available at the end of the article
}

life-history, or physiological characters. Conversely, Wimberger and de Queiroz [3] found no significant difference in evolutionary lability between morphological and behavioral traits. Therefore, relative evolutionary rates of morphological and physiological vs. behavioral traits is still being debated [4,5], and resolution may depend on the kinds of traits studied and the degree of phylogenetic resolution of focal species groups.

Among arthropods, common species-specific phenotypes that influence organismal water balance and also serve as contact pheromones, particularly in insects, are
C Biomed Central

(ㄷ) 2011 de Oliveira et al; licensee BioMed Central Ltd. This is an Open Access article distributed under the terms of the Creative Commons Attribution License (http://creativecommons.org/licenses/by/2.0), which permits unrestricted use, distribution, and reproduction in any medium, provided the original work is properly cited. 
cuticular waxes composed of hydrocarbons [6-12]. In Drosophila, epicuticular hydrocarbon $(\mathrm{CHC})$ components are usually sex-specific, species-specific and sometimes geographically variable $[7,13-18]$. These molecules are integral to the waterproofing functions of the insect cuticle, providing resistance to desiccation and water loss [19-21]. Despite the involvement of CHCs with cuticular water flux, mate recognition, and in some cases reproductive isolation, little is known about the mechanisms responsible for their larger scale diversification because few studies have investigated how correlated $\mathrm{CHC}$ differences evolve in a phylogenetic context [reviewed in [22]]. Further, the nature of $\mathrm{CHC}$ variation can be both qualitative and quantitative $[7,13,23]$ : $\mathrm{CHC}$ composition can be dynamic and change with age $[24,25]$, is influenced by temperature [24], larval-rearing substrates [26,27], and members of the opposite sex [28-31] suggesting significant sources of variation that may inhibit attempts to map their evolution onto species/population phylogenies. Using groups of populations/species in various stages of divergence is essential if we are to gauge rates of evolution across a spectrum of genetic differences including the final stages of speciation [32]. This way, we can gauge which phenotypes evolve before others, and attempt to identify causal factors responsible for divergence and perhaps the formation of new species [33].

\section{Phylogeny of the $D$. buzzatii Cluster}

We analyzed evolution of quantitative differences in $\mathrm{CHC}$ profiles in a recently diverged species group of Drosophila, the D. buzzatii cluster, in order to assess phylogenetic influences on these species-specific epicuticular hydrocarbons. This monophyletic group of cactophilic Drosophila has been previously characterized in terms of its biogeography and ecology [reviewed in [34]]. The D. buzzatii cluster is part of the mulleri complex in the large $D$. repleta group, and consists of seven closely related species including $D$. buzzatii [35], D. serido, D. borborema [36], D. koepferae [37], D. seriema [38], D. antonietae, and D. gouveai [39]. Except for cosmopolitan $D$. buzzatii, the other species are endemic to South America with most distributed in and around Brazil (Figure 1). All of these species are cryptic, where species can only be identified morphologically using male genital characteristics [39].

Monophyly of the D. buzzatii cluster was first proposed on the basis of multiple chromosomal inversions [40], with four inversions unique to different species [41]. Despite being reliable phylogenetic markers $[42,43]$, chromosomal inversions cannot resolve the relationships among some of these species, i.e. $D$. borborema, D. gouveai and D. seriema, as no inversions are unique to these taxa (Figure 2). Phylogenetic analysis of mtDNA cytochrome oxidase I (COI) sequences confirmed that these seven species form a monophyletic group $[44,45]$. However, within the cluster, not all populations of the same species were recovered in the same clade or shared the closest branches in the tree. While a mtDNA COI phylogeny partially agreed with the chromosome phylogeny, haplotype sharing among populations was observed suggesting secondary contact between $D$. antonietae and D. gouveai $[34,44]$ making these COI data less than informative for character mapping. Recently, Franco et al. [46] proposed a phylogeny for the cluster based on the nuclear period (per) gene. This phylogeny also confirmed that the $D$. buzzatii cluster forms a monophyletic group and also resolved the relationships among populations of all species including D. gouveai, D. borborema and D. seriema.

\section{Ecology and Biogeography of the $D$. buzzatii Cluster}

All species of the D. buzzatii cluster are cactophilic so their ranges are associated with the distributions of their host plants (Figure 2). D. buzzatii cluster species feed and breed exclusively in necrotic cactus tissues (rots) $[41,47]$ and some species are oligophagic, while others appear to be more specialized (Figure 2). These species are distributed throughout the caatinga and Chaco morphoclimatic domains along a corridor of arid xeromorphic vegetation extending from the northeast to the southwest between the Amazonian and Atlantic rainforests of South America. Adjacent dry forests also include cacti, but as isolated populations. These isolates are thought to have resulted from repeated retractions and expansions of open vegetation during the Quaternary glacial and interglacial periods, respectively, affecting the differentiation and speciation of D. buzzatii cluster species $[34,44]$. Nested clade analysis of Brazilian D. buzzatii cluster species suggested that these species have been distributed across Brazil at least since the Mid-Pleistocene [48]. It is likely that these climatic alterations have promoted repeated waxing and waning of cactus populations in Brazil and elsewhere in South America.

Thus, the phylogeny, biogeography, and ecology of the D. buzzatii cluster should help us to understand phenotypic evolution among populations of these recently diverged species, some that can still hybridize in nature, and how sexually dimorphic and typically species-specific $\mathrm{CHCs}$ have evolved in these species. Therefore, we characterized the variation and chemical composition of $\mathrm{CHCs}$ in all seven species in the cluster so that we could uncover the role these compounds may play in desiccation resistance and as recognition signals within and between species. By mapping $\mathrm{CHC}$ variation onto a phylogeny of these species, we show that correlated groups of CHCs show discordant patterns of evolution with some $\mathrm{CHCs}$ showing significant phylogenetic signal and others evolving more rapidly. 


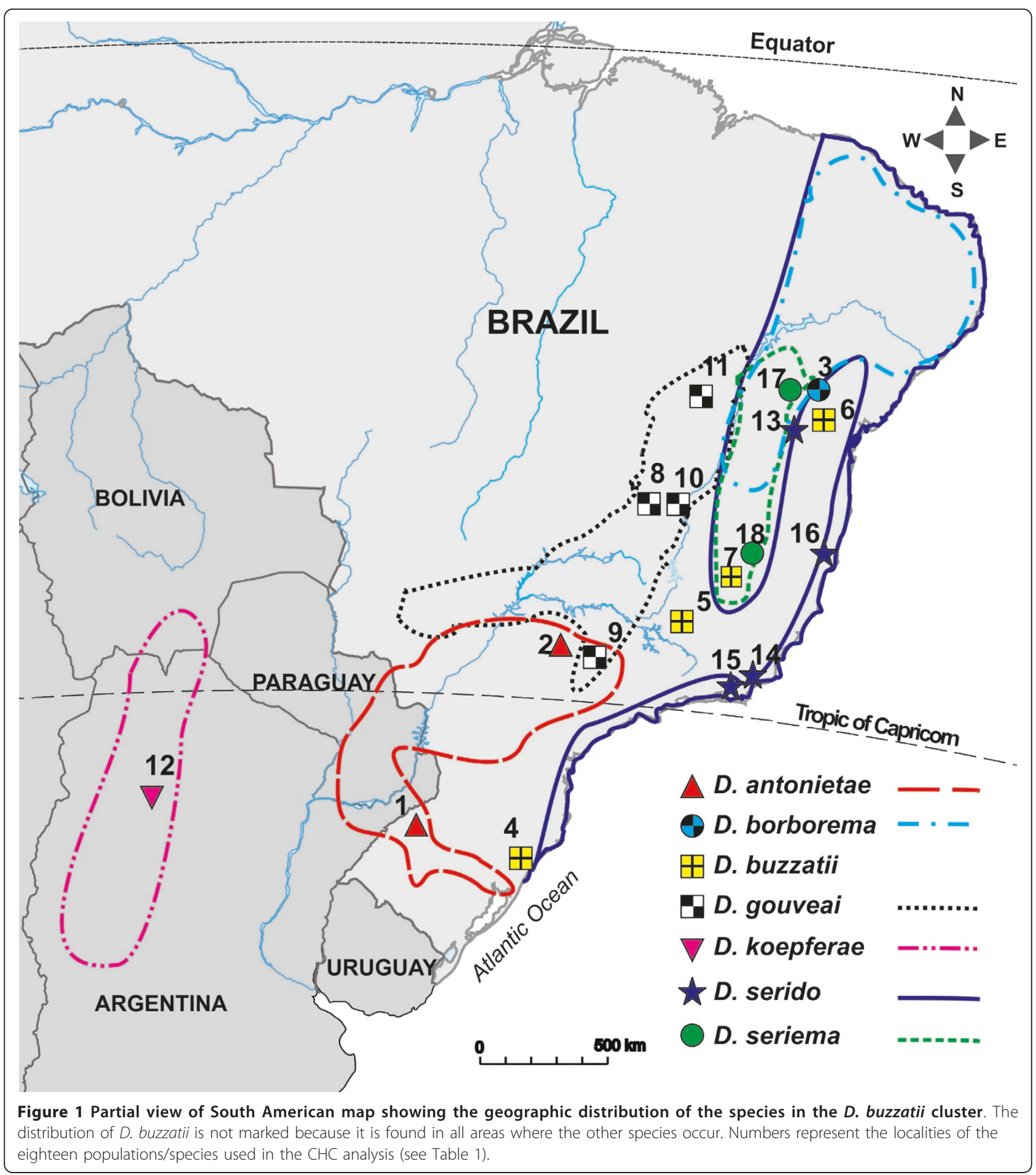

\section{Methods}

Origin and Maintenance of Fly Stocks

All populations and species were collected in the wild using fruit baits (Figure 1, Table 1) and were maintained in the Departamento de Genética, Universidade de São Paulo, Ribeirão Preto, Brazil at $\pm 25^{\circ} \mathrm{C}$ on a $12: 12$ h LD cycle on cornmeal-yeast-agar food. All emerging adults were collected from zero to two days after eclosion from each culture bottle, separated by sex using $\mathrm{CO}_{2}$ anesthesia, and placed into separate vials. Flies were aged at least 10 days before use to ensure sexual maturity. In all experiments, fly age ranged from 10 to 16 


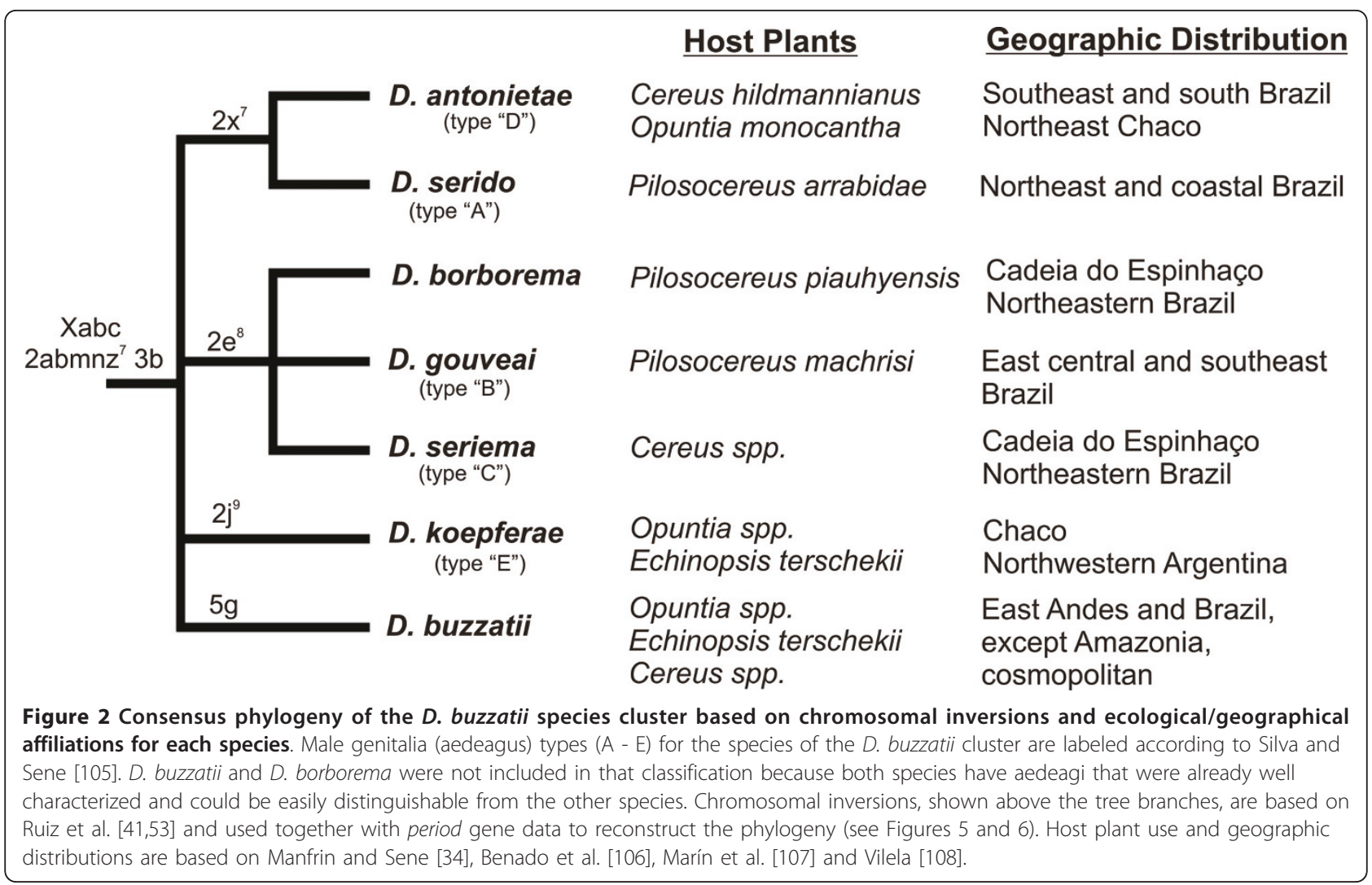

Table 1 Description of the collection sites for the $D$. buzzatii species cluster stocks used in this study.

\begin{tabular}{|c|c|c|c|c|}
\hline Species & Stock Number & $\begin{array}{c}\text { Location } \\
\text { (City and State) }\end{array}$ & Geographic Coordinates & Year of Collection \\
\hline \multirow[t]{2}{*}{ D. antonietae } & J27A6M & 1. Santiago - Rio Grande do Sul (RS) & $29^{\circ} 11^{\prime} \mathrm{S}, 54^{\circ} 50^{\prime} \mathrm{W}$ & 1998 \\
\hline & J41P1M & 2. Serrana - São Paulo (SP)* & $21^{\circ} 13^{\prime} \mathrm{S}, 47^{\circ} 35^{\prime} \mathrm{W}$ & 1999 \\
\hline D. borborema & B17.2 & 3. Morro do Chapéu - Bahia (BA)* & $11^{\circ} 56^{\prime} \mathrm{S}, 40^{\circ} 01^{\prime} \mathrm{W}$ & 1974 \\
\hline \multirow[t]{4}{*}{ D. buzzatii } & J26A45 & 4. Osório - Rio Grande do Sul (RS)* & $29^{\circ} 53^{\prime} \mathrm{S}, 50^{\circ} 10^{\prime} \mathrm{W}$ & 1998 \\
\hline & $\mathrm{J} 66 \mathrm{M} 2$ & 5. Furnas - Minas Gerais (MG) & $20^{\circ} 37^{\prime} \mathrm{S}, 46^{\circ} 15^{\prime} \mathrm{W}$ & 2000 \\
\hline & J92A21 & 6. Milagres - Bahia (BA) & $12^{\circ} 51^{\prime} \mathrm{S}, 39^{\circ} 53^{\prime} \mathrm{W}$ & 2002 \\
\hline & N57S27 & 7. Serra do Cipó - Minas Gerais (MG) & $19^{\circ} 19^{\prime} \mathrm{S}, 43^{\circ} 37^{\prime} \mathrm{W}$ & 2006 \\
\hline \multirow[t]{4}{*}{ D. gouveai } & $\mathrm{J} 18 \mathrm{M} 1$ & 8. Pirenópolis - Goiás (GO) & $15^{\circ} 51^{\prime} \mathrm{S}, 48^{\circ} 57^{\prime} \mathrm{W}$ & 1997 \\
\hline & J67M1 & 9. Analândia - São Paulo (SP) & $22^{\circ} 09^{\prime} \mathrm{S}, 47^{\circ} 42^{\prime} \mathrm{W}$ & 2000 \\
\hline & $J 75 L 11$ & 10. Cristalina - Goiás (GO) & $16^{\circ} 46^{\prime} \mathrm{S}, 47^{\circ} 36^{\prime} \mathrm{W}$ & 2001 \\
\hline & J78M1 & 11. Ibotirama - Bahia $(B A)^{*}$ & $12^{\circ} 16^{\prime} \mathrm{S}, 43^{\circ} 04^{\prime} \mathrm{W}$ & 2001 \\
\hline D. koepferae & B20D2 & 12. Tapia - Tucumán (TU)* & $26^{\circ} 32^{\prime} \mathrm{S}, 65^{\circ} 15^{\prime} \mathrm{W}$ & 1970 \\
\hline \multirow[t]{4}{*}{ D. serido } & J92A91M & 13. Milagres - Bahia $(\mathrm{BA})^{*}$ & $12^{\circ} 51^{\prime} \mathrm{S}, 39^{\circ} 53^{\prime} \mathrm{W}$ & 2002 \\
\hline & N20A3 & 14. Arraial do Cabo - Rio de Janeiro (RJ) & $22^{\circ} 57^{\prime} \mathrm{S}, 42^{\circ} 01^{\prime} \mathrm{W}$ & 2004 \\
\hline & $\mathrm{N} 21 \mathrm{M} 1$ & 15. Macaé - Rio de Janeiro (RJ) & $22^{\circ} 19^{\prime} \mathrm{S}, 41^{\circ} 45^{\prime} \mathrm{W}$ & 2004 \\
\hline & N34M3 & 16. Mucuri - Bahia (BA) & $17^{\circ} 58^{\prime} \mathrm{S}, 39^{\circ} 29^{\prime} \mathrm{W}$ & 2005 \\
\hline \multirow[t]{2}{*}{ D. seriema } & D40F1 & 17. Morro do Chapéu - Bahia (BA)* & $11^{\circ} 56^{\prime} \mathrm{S}, 40^{\circ} 01^{\prime} \mathrm{W}$ & 1990 \\
\hline & N57S4 & 18. Serra do Cipó - Minas Gerais (MG) & $19^{\circ} 19^{\prime} \mathrm{S}, 43^{\circ} 37^{\prime} \mathrm{W}$ & 2006 \\
\hline
\end{tabular}

All 18 populations were used for $\mathrm{CHC}$ quantification. One population of each species, indicated by an asterisk $(*)$, was used for $\mathrm{CHC}$ characterization by gas chromatography-mass spectrometry (GCMS). Thirteen out of 18 populations had data available for both per gene and CHCs and were used for phylogenetic reconstruction (shown as underlined). Except for D. koepferae from Argentina, all other populations were collected in Brazil. 
days. All procedures, experiments, and $\mathrm{CHC}$ extractions requiring live flies were carried out in the Sene-Manfrin laboratory in Ribeirão Preto because current Brazilian regulations prohibit exporting these species. $\mathrm{CHC}$ quantification was performed at the University of Arkansas and $\mathrm{CHC}$ characterization by gas chromatography-mass spectrometry (GCMS) was carried out at Montana State University. Despite observations that rearing substrates can influence $\mathrm{CHC}$ profiles $[17,26]$, it was not possible to assess $\mathrm{CHC}$ variation with cactus-reared flies as host plant-microbe relationships necessary to culture all of these species on fermenting cactus tissues are not well studied. As all flies were cultured under common laboratory conditions, $\mathrm{CHC}$ variation should reflect population, sex, and species differences.

\section{Chemical Analysis of CHCs}

One population of each species (Table 1) was used to identify epicuticular hydrocarbon components in males and females. The most abundant $\mathrm{CHCs}$ were characterized by GCMS following Etges and Jackson [7]. In short, hundreds of adults of each species were separated by sex, allowed to mature, and then rinsed with HPLC grade hexane in Biosil ${ }^{\mathrm{TM}}$ mini-columns. Extracts were dried at $40^{\circ} \mathrm{C}$ under a stream of nitrogen and sealed/ stored at $-20^{\circ} \mathrm{C}$. Each extract was analyzed with a Hewlett Packard 5890 GC fitted with a 12-m HP-1 fused silica column programmed at $150^{\circ} \mathrm{C}$ to $300^{\circ} \mathrm{C}$ at $10^{\circ} \mathrm{C} /$ min and held at $300^{\circ} \mathrm{C}$ for $5 \mathrm{~min}$. The injector and detector temperature (Hewlett Packard 5971 mass selective detector) was $280^{\circ} \mathrm{C}$. Extracts were redissolved in hexane containing $100 \mathrm{ng} /$ fly of docosane $\left(\mathrm{C}_{22}\right)$ as an internal standard. The unsaturated $\mathrm{CHCs}$ were derivatized with dimethyl disulfide (DMDS), and the resulting thiomethyl derivatives were analyzed by GCMS to identify the positions of the double bonds [24].

\section{CHC Variation among Populations and Species}

Eighteen populations, including at least one geographical stock of each species, were used to quantify variation in male and female $\mathrm{CHCs}$. Preliminary $\mathrm{CHC}$ classification was determined by comparing the retention times of each observed CHC component from the D. buzzatii cluster species with those of the $D$. mojavensis cluster [7]. In all cases, the retention times of most of the major $\mathrm{CHCs}$ were very similar to those of $D$. mojavensis indicating a remarkable degree of $\mathrm{CHC}$ conservation among these distantly related species groups. Ten aged, virgin adult flies for each sex of 18 different populations (Table 1) were individually immersed in HPLC hexane for 10 minutes with agitation, dried at $40^{\circ} \mathrm{C}$, stored at $-20^{\circ} \mathrm{C}$, and returned to the University of Arkansas. Each extract was redissolved in $5 \mu \mathrm{l}$ heptane containing 360 ng of docosane $\left(\mathrm{C}_{22}\right)$ as an internal standard [26]. One $\mu \mathrm{l}$ of sample was analyzed by capillary gas-liquid chromatography in an automated Shimadzu GC-17H High Speed FID/GC fitted with an AOC-20i autosampler (Shimadzu Scientific, Columbia, MD). Injector and detector temperatures were set to $345^{\circ} \mathrm{C}$ with the injector port in split mode. Running temperatures started at $200^{\circ} \mathrm{C}$ and increased to $345^{\circ} \mathrm{C}$ at $10^{\circ} \mathrm{C} / \mathrm{min}$, with a hold at $345^{\circ} \mathrm{C}$ for $7 \mathrm{~min}$ [49].

\section{Statistical Analyses}

$\mathrm{CHC}$ amounts were estimated by analysis of peak integrations using Class VP 4.2 software provided by Shimadzu. Each sample amount was normalized by the measured amount of docosane and all data were expressed as nanograms per fly of CHCs. We quantified amounts of 36 peaks in each sample after eliminating 18 peaks with areas that accounted for less than $1 \%$ of the total hydrocarbon abundance in at least one fly in all populations. All data were assessed for normality with PROC UNIVARIATE using SAS 9.1 [50] and $\log _{10}$ transformations improved normality. Nested multivariate analysis of variance was used to assess $\mathrm{CHC}$ variation among species and populations nested within species were considered random effects. The main effects in the model included species, sex and population nested within species and the interactions were species $\times$ sex and $\times$ population nested within species.

Five canonical discriminant function (CDF) analyses (PROC CANDISC) were performed to summarize CHC variation along continuous scales representing orthogonal axes of $\mathrm{CHC}$ covariation that best separated populations/species and to help visualize group differences. Out of the 36 peaks scored, 15 minor peaks were eliminated prior to the CDF analyses due to missing values. Consequently, a total of 21 peaks were used in the five different CDF analyses performed. First, we carried out a CDF analysis using all data, i.e. 18 populations/species (Table 1) to explore the overall magnitude of $\mathrm{CHC}$ differentiation in our data. This procedure was followed by a linear discriminant function analysis (PROC DISCRIM) using the same dataset to classify individuals based on species, population and sex. Second, we performed a CDF analysis without the four populations of $D$. serido, i.e. 14 populations/species, due to large, unanticipated intraspecific $\mathrm{CHC}$ variation in this species (see results). Third, we used CDF analysis to generate CVs for character mapping, i.e. for those populations used in the phylogenetic reconstruction (see description below). Thirteen out of 18 populations from which data was available for both per gene and CHCs were used in the character evolution analysis. In this third analysis, besides the 13 populations/species of the D. buzzatii cluster we also included the three species of the $D$. mojavensis cluster. We did not pool the sexes (as in the 
first and second CDF analyses) because we were interested in sex-specific $\mathrm{CHC}$ evolution. We performed the CDF analysis with females and males together so that male and female species-specific CDF scores could be compared on a common scale, but separated the data by sex to evaluate $\mathrm{CHC}$ evolution in the character reconstruction analyses. Finally, a fourth and fifth CDF analyses were also used in character mapping and were similar to the third analysis, except that in the fourth analysis we did not include the species of the D. mojavensis cluster and in the fifth analysis the $D$. serido populations were excluded. For all five CDF analyses, Pearson correlation coefficients were calculated between individual $\mathrm{CHC}$ amounts and canonical scores for each $\mathrm{CHC}$ for the first five CVs with PROC CORR to determine which $\mathrm{CHC}$ peaks were significantly associated with these canonical variates. Lastly, we conducted stepwise discriminant analyses (PROC STEPDISC) for each of the five datasets used in the CDF analyses to evaluate which $\mathrm{CHC}$ peaks most contributed to the variation between populations.

\section{Mantel Tests}

We were also interested in whether geographic distance between populations distributed over such a large area (Figure 1) might explain some of the interspecific variation in $\mathrm{CHCs}$ due to factors like ambient ecological differences, sexual selection, or genetic drift. Our null hypothesis was that geographic distance measured in kilometers should be unrelated to overall $\mathrm{CHC}$ differences between populations. We performed Mantel tests using Manteller software [51] and compared female and male $\mathrm{CHC}$ matrices based on Euclidean distances with a geographic distance matrix of 18 populations/species. Pair-wise, great circle distances between populations were calculated using the "Haversine" formula [52].

\section{Phylogenetic Reconstruction}

Originally, we combined chromosomal inversion differences [41,53] with the per gene [46] and mtDNA COI sequence data [44] to reconstruct phylogenetic relationships for the seven D. buzzatii cluster species. Chromosome inversions have high phylogenetic utility in Drosophila [42], but because only four inversions are unique and thus phylogenetically informative in the $D$. buzzatii species cluster (Figure 2), populations of the same species were all coded with the same inversions. For all species, inversions were coded as present (1) or absent (0). Although the phylogeny based on COI sequences did not recover all populations of the same species in the same clade [44], we thought the mtDNA data could still be useful in combination with chromosomal inversions and the per gene. However, the phylogeny produced by combining all three data sets was clearly driven by the COI sequence data (Additional File 1: Figure S1). We followed Santos et al. [54] in concluding that these mtDNA COI data did not provide clear phylogenetic relationships for these species, either alone or when combined with nuclear markers. Thus, only per + inversion data were used in the phylogenetic reconstruction.

We only used populations/species from the $D$. buzzatii cluster from which per gene and $\mathrm{CHC}$ data were available (13 out of 18 populations) since the reconstructed phylogeny was used later to study $\mathrm{CHC}$ evolution (see below). Populations used in the per phylogeny [46] are indicated in Table 1. We also included two species used as outgroups by Franco et al. [46], i.e. D. mojavensis and D. hydei. Because no $\mathrm{CHC}$ data were available for $D$. hydei this species was removed before the tree was used for reconstruction of $\mathrm{CHC}$ evolution. The published per sequences were aligned using Mega version 4 [55]. Phylogenetic analysis of the per gene + chromosomal inversion data was performed using PAUP* 4.0 [56]. Maximum parsimony was used to search for optimal tree(s) and heuristic searches were carried out with 100 random addition analyses and tree bisection reconnection (TBR) branch swapping. Nodal support was obtained using bootstrap analysis (1,000 replicates).

\section{Mapping CHCs onto the Phylogeny}

Patterns of character evolution were inferred by mapping $\mathrm{CHC}$ canonical variates $(\mathrm{CVs})$ (See Statistical Analyses) onto the reconstructed phylogeny using Mesquite 2.6 [57]. The CVs were mapped onto the first out of six most parsimonious trees instead of the strict consensus tree because one of the models used, Squared Change Parsimony Gradual (see below), relies on branch length information. Besides D. mojavensis, we also added the other two species of the $D$. mojavensis cluster, $D$. arizonae and $D$. navojoa, as a sister group to the D. buzzatii cluster. We included the $D$. mojavensis cluster in the analysis because its phylogeny is well established $[58,59]$, $\mathrm{CHC}$ data were available [7], and we were interested in its evolution as well. Because the number of species used in the phylogeny can influence the detection of phylogenetic signal [2] where higher numbers of species (17 - 20) can increase the power of the analysis, adding these species is justified and should help to avoid type II error, i.e. failure of rejecting the null hypothesis of no phylogenetic signal when in reality there was a significant relationship between $\mathrm{CHC}$ profiles and the phylogeny. We also performed two other character reconstruction analyses: one with just the populations/ species of the D. buzzatii cluster and another without the populations of $D$. serido. In the former analysis we wanted to assess patterns of character evolution without the effects of outgroup species and in the latter analysis 
without the influence of these highly divergent populations.

Because reconstruction methods have different assumptions, they can lead to different reconstructions of ancestral states [60-62] and also influence the detection of phylogenetic signal. Therefore, we decided to employ three different parsimony methods, i.e. Linear Parsimony (LP), Squared Change Parsimony Gradual (SCPG), and Squared Change Parsimony Punctuated (SCPP) to determine whether they would yield different results. LP algorithms minimize the sum of the absolute values of changes on the branches of the tree [63]. The LP method does not use branch length information and assumes stabilizing selection as the model of evolutionary change [60]. Both SCPG and SCPP algorithms [64] minimize the sum of the squared changes on the branches of the tree. The SCPG method calculates squared changes based on branch lengths from the reconstructed tree assuming a Brownian motion model, i.e. steady gradual change (SCPG). Conversely, SCPP produces squared changes based on all branches lengths set to one with equal rates of evolution along each branch to simulate a model of punctuated evolution, where changes occur at speciation events $[60,65,66]$.

We assessed congruence between the $\mathrm{CHC}$ canonical variates and the phylogeny (reference tree) by testing for the degree of phylogenetic signal revealed by these parsimony methods. Our null hypothesis was that non-phylogenetic influences such as developmental noise, ecological effects such as rearing conditions, or speciesspecific sexual selection have shaped $\mathrm{CHC}$ profiles such that $\mathrm{CHC}$ evolution was independent of species evolution. Our alternative hypothesis was that significant phylogenetic signal should be observed due to the phylogenetic affinities of these populations and so $\mathrm{CHC}$ variation should be correlated with species evolution. Evidence for phylogenetic signal in our data was evaluated in all three parsimony reconstruction algorithms by randomly modifying the reference tree, i.e. reshuffling the terminal taxa 10,000 times to generate a population of random trees for each character (female and male CVs). These trees with reshuffled taxa were then compared with the reference tree to test whether $\mathrm{CHC}$ distributions were more conserved than expected by chance alone. We concluded that there was phylogenetic signal if the number of parsimony character steps in the reference tree was less than in $95 \%$ of the trees with reshuffled taxa, i.e. values that fell on the extreme left of the distribution had fewer changes than expected by chance (Additional File 2: Figure S2). Alternatively, if $\mathrm{CHC}$ variation among closely related species was less than expected given their phylogenetic affinities, i.e., if the mean parsimony character steps for the reference tree fell on the extreme right of the reshuffled distribution, we interpreted this outcome as a result of more $\mathrm{CHC}$ differentiation than expected by chance alone [see [67] for details].

The detection of phylogenetic signal was also examined with the test for serial independence (TFSI), described in Abouheif [68], and available in the program Phylogenetic Independence 2.0 [69]. We decided to use TFSI as an alternative to the parsimony models because it does not assume a model of evolutionary change or require branch lengths. While this can be problematic because topology alone cannot provide all information about species similarity [2], it can be a strength if the branch lengths or model of evolutionary change are not known or accurate [68]. Furthermore, parsimony results can be misleading if the model of evolutionary change differs significantly from gradual change, i.e. when rates of evolution are rapid and/or rates of gains and losses are not equal $[60,62]$. For all three parsimony methods and TFSI, $p$-values were corrected for multiple comparisons via false discovery rate (FDR) analysis [70,71].

\section{Results}

\section{Chemical Composition of $\mathrm{CHCs}$}

All seven species and both sexes in the D. buzzatii cluster had $\mathrm{CHCs}$ with carbon chain lengths ranging from $\mathrm{C}_{29}$ to $\mathrm{C}_{39}$ (Additional File 3: Figure S3). The CHCs of adult flies were composed of three structural classes: mono-methyl-branched alkanes, $n$-alkenes, and alkadienes (Table 2). Mono-methyl-branched alkanes comprised both the $\mathrm{C}_{28.65}$ and $\mathrm{C}_{30.65}$ peaks. The former had the same composition for all species and both sexes (i.e. 2-methyloctacosane), while the latter varied among species, composed of either a mono-methyl-branched alkane (2-methyltriacontane) or $n$-alkenes [(Z)-5-hentriacontene or (Z)-9-hentriacontene]. In fact, $C_{30.65}$ was one of the four peaks showing qualitative differences between sexes, i.e., $C_{30.65}$ was composed of 2-methyltriacontane in D. gouveai $\sigma^{\prime \prime}, D$. seriema $\$$ and $D$. koepferae \&, but composed of (Z)-9-hentriacontene in D. gouveai Q, D. seriema $0^{\prime \prime}$ and $D$. koepferae on. Peaks $C_{37}$ and $C_{36.5}$ were also sexually dimorphic, but results were only available for D. gouveai (Table 2).

All other observed peaks were composed of either monoenes or dienes. Several peaks were comprised of mixtures of positional monoene isomers (Table 2) where the location of double bonds was mainly at even-numbered carbons (e.g. ( $Z$ )-8-tritriacontene and ( $Z$ )-10-pentatriacontene). Alkadienes were also present in more than one positional isomer, but the double bonds were located mostly at odd-numbered carbons (e.g. $(Z, Z)$ 7,25-tritriacontadiene and $(Z, Z)$-5,25-pentatriacontadiene). The composition of some peaks was not determined because these samples proved difficult to derivatize with DMDS. 
Table 2 Key mass spectra peaks used in the identification of CHCs from the $D$. buzzatii species cluster.

\begin{tabular}{|c|c|c|c|c|c|}
\hline \multirow[b]{2}{*}{$\begin{array}{l}\text { Carbon } \\
\text { Number }\end{array}$} & \multirow[b]{2}{*}{$\mathrm{ECL}^{\mathrm{a}}$} & \multirow[b]{2}{*}{ Hydrocarbon $^{b}$} & \multicolumn{2}{|c|}{ Diagnostic ions $(\mathrm{m} / \mathrm{z})$} & \multirow[b]{2}{*}{ Notes $^{c}$} \\
\hline & & & Untreated & $\begin{array}{l}\text { Dimethyl Disulfide } \\
\text { Derivative }\end{array}$ & \\
\hline 29 & 28.65 & 2-methyloctacosane & $\begin{array}{l}365,393 \\
\quad 408\end{array}$ & & All species and sex \\
\hline \multirow[t]{3}{*}{31} & 30.65 & 2-methyltriacontane & $\begin{array}{l}393,421 \\
436\end{array}$ & & $\begin{array}{l}\text { D. serido O; D. gouveai ơ; D. seriema O; D. } \\
\text { koepferae o; D. antonietae \&and ơ }\end{array}$ \\
\hline & & (Z)-5-hentriacontene & 434 & 117,411 & D. serido o \\
\hline & & (Z)-9-hentriacontene & 434 & 173,355 & $\begin{array}{c}\text { D. gouveai o; D. seriema ơ; D. koepferae ơ; D. } \\
\text { buzzatii ơ }\end{array}$ \\
\hline \multirow[t]{7}{*}{33} & $\begin{array}{c}33 \\
b r 3\end{array}$ & (Z)-14-; (Z)-12-; and (Z)-10-tritriacontene & 462 & $\begin{array}{c}187,215,243,313 \\
341,369\end{array}$ & 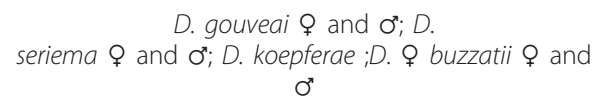 \\
\hline & & (Z)-16-; (Z)-15-tritriacontene & 462 & & D. koepferae o \\
\hline & 32.47 & (Z)-8-tritriacontene & 462 & 159,397 & All species and sex, except D. antonietae $Q$ and $\sigma^{n}$ \\
\hline & 32.56 & (Z)-6-tritriacontene & 462 & 131,425 & $\begin{array}{c}\text { All species and sex, except } D \text {. serido } 9 D . \\
\text { antonietae } \$ \text { and } \sigma^{*}\end{array}$ \\
\hline & 32.79 & (Z, Z)-5,25-tritriacontadiene & 460 & 117,437 & D. serido $\odot$ and $\sigma^{\prime \prime}$ \\
\hline & & (Z, Z)-7,25-tritriacontadiene & 460 & 145,409 & $\begin{array}{c}\text { D. gouveai } q \text { and } \sigma^{*} ; \text { D. seriema } q \text { and } \sigma^{\pi} ; D \text {. } \\
\text { koepferae } q\end{array}$ \\
\hline & 32.86 & (Z, Z)-7,25-tritriacontadiene & 460 & 131,423 & D. serido $\odot$ and $\sigma^{n}$ \\
\hline 34 & $\begin{array}{l}34 \\
\text { ene }\end{array}$ & (Z)-16-; (Z)-14-tetratriacontene & 474 & $\begin{array}{l}215,243,271,299 \\
327,355\end{array}$ & $\begin{array}{c}\text { D. gouveai } q \text { and } \sigma^{*} ; \text { D. koepferae } \$ \text { and } \sigma^{*} ; D . \\
\text { buzzatii } \$ \text { and } \sigma^{*}\end{array}$ \\
\hline \multirow[t]{11}{*}{35} & $\begin{array}{l}35 \\
\text { ene } 1\end{array}$ & (Z)-16-; (Z)-14-; (Z)-12-pentatriacontene & 490 & $\begin{array}{c}215,243,271,313 \\
341,369\end{array}$ & D. gouveai $q$ and $\sigma^{\pi} ;$ D. seriema $\$$ and $o^{\pi}$ \\
\hline & & (Z)-16-; (Z)-14-pentatriacontene & 490 & $243,271,313$ & D. koepferae $\odot$ and $\sigma^{\prime \prime}$ \\
\hline & & (Z)-14-; (Z)-12-pentatriacontene & 490 & $215,243,341,369$ & D. buzzatii \& \\
\hline & $\begin{array}{l}35 \\
\text { ene } 2\end{array}$ & (Z)-10-pentatriacontene & 490 & 187,397 & $\begin{array}{c}\text { All species except D. serido } Q \text { and D. antonietae } Q \\
\text { and } \sigma^{*}\end{array}$ \\
\hline & $\begin{array}{l}35 \\
\text { ene } 3\end{array}$ & (Z)-8-pentatriacontene & 490 & 159,425 & $\begin{array}{c}\text { All species except D. serido } Q \text { and D. antonietae } q \\
\text { and } \sigma^{*}\end{array}$ \\
\hline & 34.66 & (Z, Z)-5,25-pentatriacontadiene & 488 & 187,395 & D. serido $\odot$ and $\sigma^{n}$ \\
\hline & & $\begin{array}{c}\text { (Z, Z)-9,25-pentatriacontadiene or }(Z, Z) \text { - } \\
\text { 9,27-pentatriacontadiene }\end{array}$ & 488 & 173,423 & D. gouveai $\$$ and $\sigma^{*}$ \\
\hline & & (Z, Z)-8,26-pentatriacontadiene & 488 & 159,409 & D. seriema $Q$ and $\sigma^{\pi}$ \\
\hline & 34.79 & (Z, Z)-7,27-pentatriacontadiene & 488 & 145,437 & D. serido $\%$ and $O^{n}$ \\
\hline & & $\begin{array}{c}\text { (Z, Z)-7,27-pentatriacontadiene or }(Z, Z) \text { - } \\
\text { 7,25-pentatriacontadiene }\end{array}$ & 488 & 145,437 & D. gouveai $\$$ and $\sigma^{\pi}$ \\
\hline & & (Z, Z)-6,28-pentatriacontadiene & & 131,453 & D. seriema o" \\
\hline \multirow[t]{5}{*}{37} & 37 & (Z)-16-; (Z)-18-; (Z)-14-heptatriacontene & 517 & $\begin{array}{c}243,271,299,313 \\
341,369\end{array}$ & D. gouveai on \\
\hline & & (Z, Z)-10,23-Heptatriacontadiene & 517 & 187,423 & D. gouveai q \\
\hline & 36.5 & (Z)-16-; (Z)-18-; (Z)- 14-heptatriacontene & 517 & $\begin{array}{c}243,271,299,313 \\
341,369\end{array}$ & D. gouveai o" \\
\hline & & (Z, Z)-9,27-heptatriacontadiene & 517 & 173,437 & D. gouveai o \\
\hline & 36.7 & (Z)-16-; (Z)-18-; (Z)-14-heptatriacontene & 517 & $\begin{array}{l}243,271,299,313 \\
341,369\end{array}$ & D. gouveai $q$ and D. gouveai $\sigma^{*}$ \\
\hline
\end{tabular}

Only major peaks were scored. See Table 1 for description of the populations used.

${ }^{a}$ Equivalent chain length calculated as in Stennett and Etges [26].

${ }^{b}$ Isomer order ranges from major to minor abundance.

c Species/sexes that are not included had hydrocarbons that could not be identified.

\section{Quantitative Variation in CHC Profiles}

Quantitative variation in CHCs was much more prominent than chemical differences between species. $\mathrm{CHC}$ variation due to sex, species, and population and all interactions were significant (Table 3). Out of the 36 peaks analyzed, 12 major peaks accounted for ca $85 \%$ of the total hydrocarbons for all 18 populations/sexes analyzed (Additional File 4: Table S1). Mean total hydrocarbon amount per fly was $878.68 \mathrm{ng} \pm 21.71(\overline{\mathrm{X}} \pm 1 \mathrm{SE})$. All pair-wise squared Mahalanobis distances between 
Table 3 Nested MANOVA results for 36 CHC peaks in 18 populations/species of $D$. buzzatii cluster species.

\begin{tabular}{cccccc}
\hline Source of Variation & Wilks $\boldsymbol{\lambda}$ & $\boldsymbol{F}$ value & $\mathbf{d f}$ & $\boldsymbol{P}$ \\
\hline Species & 0.0000 & 130.35 & $216,1099.6$ & $<0.0001$ \\
Sex & 0.1944 & 21.18 & 36,184 & $<0.0001$ \\
Population(Species) & 0.0000 & 21.91 & $396,1973.9$ & $<0.0001$ \\
Sex $\times$ Population(Species) & 0.0018 & 4.09 & $396,1973.9$ & $<0.0001$ \\
Species $\times$ Sex & 0.0017 & 9.87 & $216,1099.6$ & $<0.0001$ \\
\hline
\end{tabular}

Population effects were nested within species.

species were significant $(P<0.0001)$, as were differences among populations (Wilks $\lambda=0.0000, F=57.11, P<$ $0.0001)$. MANOVA revealed significant species and population specific sexual dimorphism revealed by a species $\times$ sex interaction term (30/36 peaks) and sex $\times$ population nested within species term (27/36 peaks) (results not shown). Thus, sexual dimorphism in CHC profiles was a significant source of variation in populations of all seven species. Linear discriminant function analysis based on 18 populations/species correctly assigned $98.2 \%$ and $96.6 \%$ of individuals (out of 298 total) to their correspondent populations and species, respectively. The classification based on sex correctly assigned $76 \%$ and $80 \%$ of females and males, respectively. Therefore, $\mathrm{CHC}$ variation in the D. buzzatii cluster was largely species-, population-, and sex-specific.

The first five canonical variates from the CDF analysis for all 18 populations/species accounted for $94 \%$ of the total hydrocarbon variation (Additional File 5: Table S2) and grouped populations of the same species together except for $D$. serido populations that were highly divergent and showed large discordance with the other populations/species (Figure 3A). The first canonical variate (CV1) was largely influenced by the divergence among $D$. serido populations. All four populations of $D$. serido differed significantly in $\mathrm{CHC}$ composition, and three of these populations were more different from each other than most of the other species (Figure 3A). D. serido populations from Mucuri, Bahia and Arraial do Cabo, Rio de Janeiro (Figure 1) clustered together but were isolated from all other populations/species. The Milagres, Bahia population of $D$. serido was the most divergent population in the analysis and was completely isolated from all other populations/species including the other $D$. serido populations. The fourth population of $D$. serido, from Macaé, Rio de Janeiro, had CHC profiles similar to those of D. buzzatti populations (Figure 3A). Therefore, we suspected that the Macaé population was contaminated with $D$. buzzatii in lab culture because this population was collected less than $100 \mathrm{~km}$ away from Arraial do Cabo (populations 14 and 15, Figure 1, Table 1), and it is unlikely that these two populations would be so different in $\mathrm{CHC}$ profiles. The second canonical variate (CV2) separated populations of the same species, but was still dominated by the striking differences caused by the $D$. serido populations. Since $D$. serido was apparently causing so much of the overall $\mathrm{CHC}$ variation and obscuring the differences between the other species, we performed a second CDF analysis excluding all four $D$. serido populations (Additional File 6: Table S3). We observed not only reduced total variation in this analysis (see axis range in Figure 3B) but also a clearer separation of the species (CV1) and populations of the same species (CV2). Overall, the striking degree of intraspecific $\mathrm{CHC}$ variation found in $D$. serido populations suggests the presence of at least two cryptic "D. serido" lineages.

We also attempted to identify which $\mathrm{CHCs}$ were responsible for these striking population/species differences. First, we used stepwise discriminant function analysis with both forward and reverse variable entry to identify which of the $21 \mathrm{CHC}$ peaks was/were driving the differences among populations. All but one of the $21 \mathrm{CHC}$ components were significantly correlated with the discriminant function, $P<0.0001$, with partial correlations of 0.149 to 0.905 (Additional File 7: Table S4). Next, we sequentially deleted individual peaks and performed additional CDF analyses in an attempt to identify which $\mathrm{CHCs}$ caused the large differences due to $D$. serido (Figure $3 \mathrm{~A}$ ). We started by removing the $C_{30.83}$ component, a $\mathrm{CHC}$ with one of the largest partial correlations with the discriminant function (Additional File 7: Table S4) that was found in significantly higher amounts in D. serido populations from Mucuri and Arraial do Cabo (Figure 4), but was absent or in negligible amounts in all other populations/species (Additional File 4: Table S1). Removal of the $C_{30.83}$ peak did not eliminate the large $D$. serido population differences so we deleted another large component, $\mathrm{C}_{32.47}$, which resulted in eliminating most of the $\mathrm{CHC}$ differences that separated $D$. serido from Milagres, Bahia from the other species (results not shown). Thus, there were population-specific $\mathrm{CHCs}$ that seemed to be driving these extraordinary intraspecific differences in $\mathrm{CHCs}$, but the general pattern of $\mathrm{CHC}$ differentiation between these populations involved quantitative variation in most of the CHCs scored. Results of the Mantel tests [51] assessing associations between $\mathrm{CHC}$ differentiation among populations/species and geographic distance were not significant (females: $\mathrm{r}=-0.049, P=0.596$; males: $\mathrm{r}=$ $0.078, P=0.784)$.

\section{Phylogenetic Reconstruction and CHC Character Mapping} The parsimony analysis resulted in six equally most parsimonious per gene + chromosome inversion trees (Additional File 8: Figure S4) of 166 steps $(\mathrm{CI}=0.82$; RI $=0.76)$. The strict consensus tree (Figure 5) 


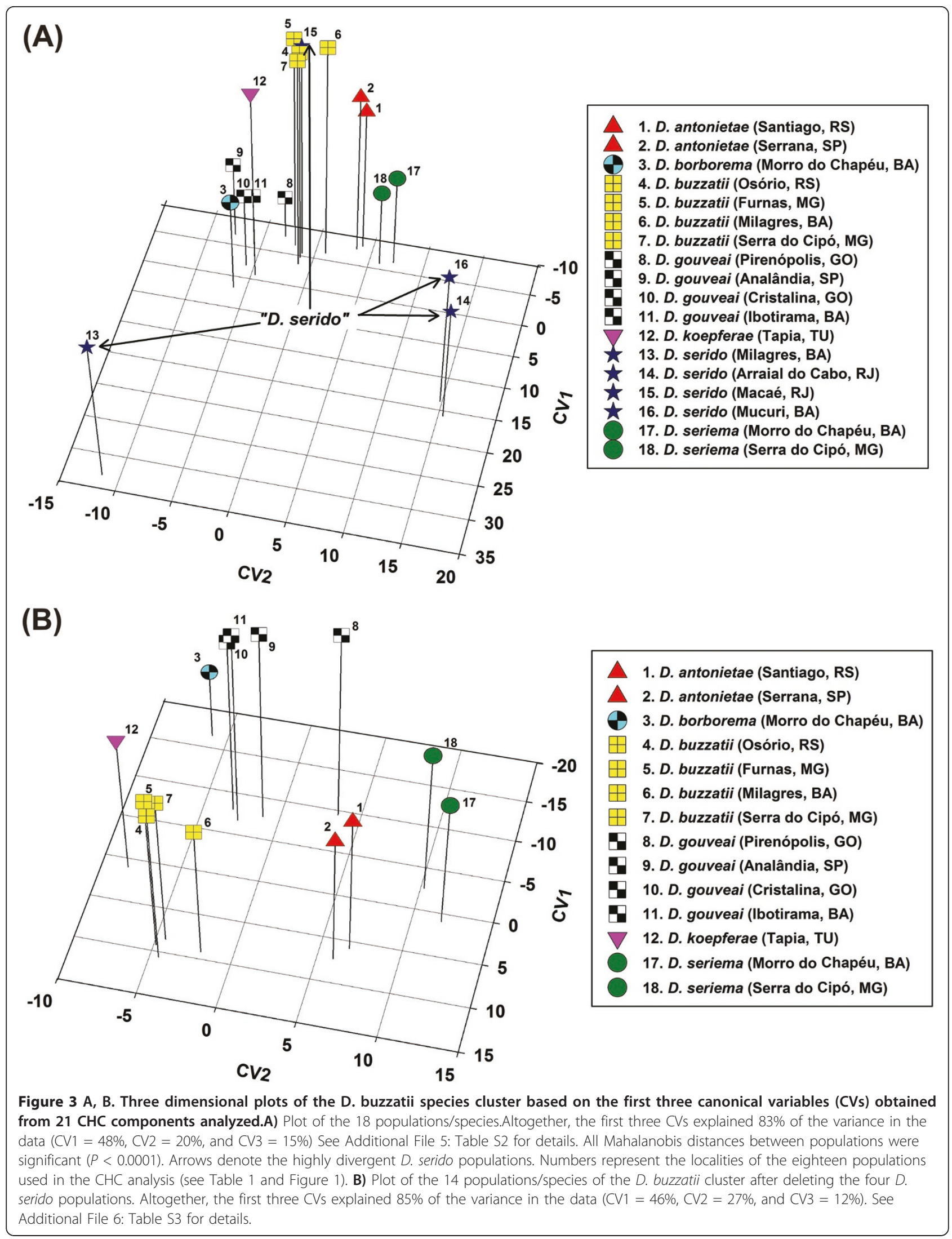




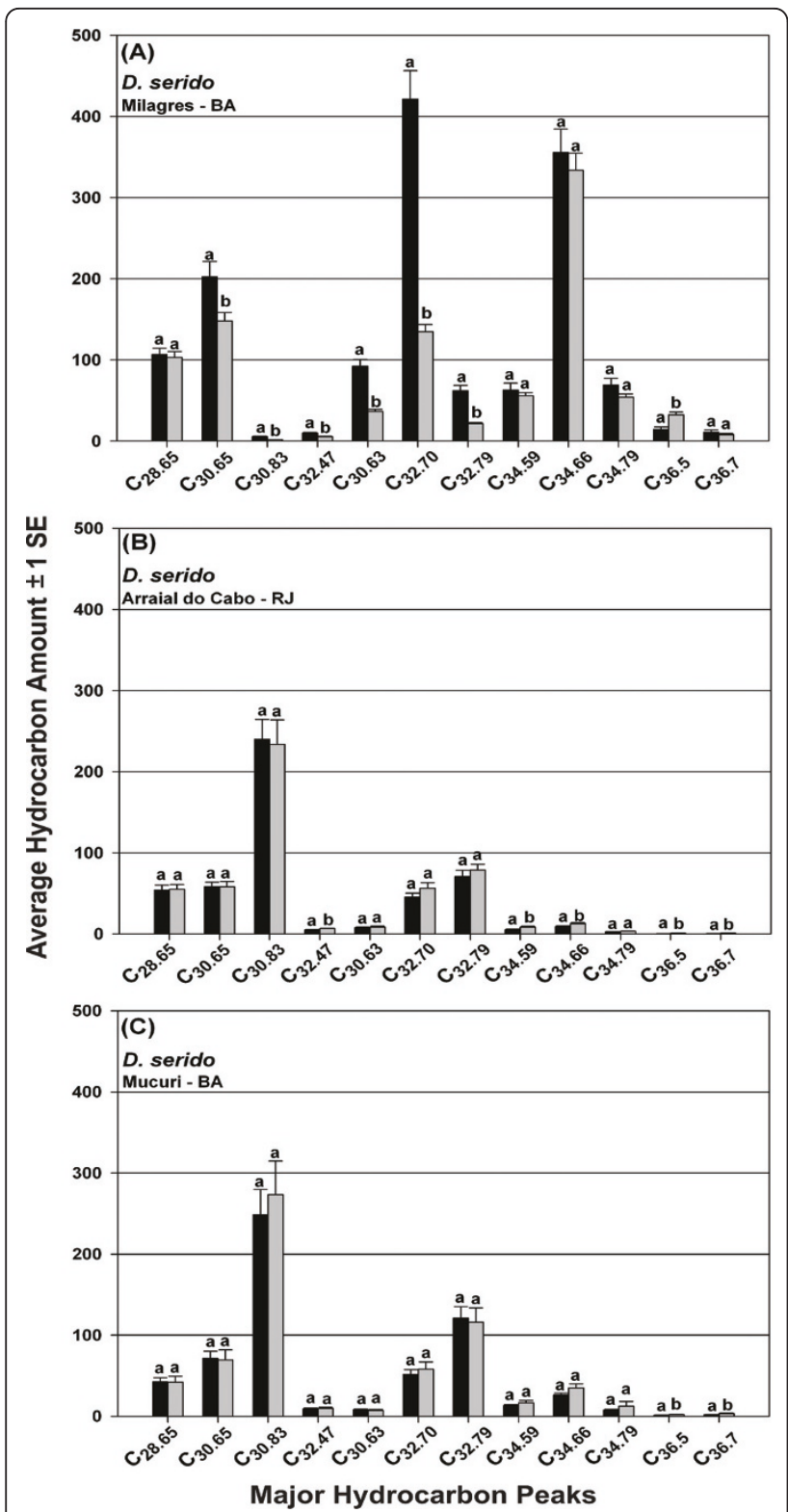

Figure $4 \mathrm{~A}-\mathrm{C}$. Epicuticular hydrocarbon amounts (average \pm 1 $\mathrm{SE}$ ) for 12 major hydrocarbon peaks of females (black) and males (gray) of 3 populations of $D$. serido ( $D$. serido from Macaé is not shown). For each peak same letters represent nonsignificant means between females and males. Components are referred to by their equivalent chain lengths.

produced a well-resolved phylogeny that clustered all populations/species of the $D$. buzzatii cluster together (bootstrap value 99\%). We decided to use the first out of six most parsimonious trees for character mapping because this tree was the one that closest resembled the strict consensus tree. In fact, all six parsimony trees had very similar topologies (Additional File 8: Figure S4). Tree 1 and tree 2 had the same topology except that tree 2 had a polytomy in the clade containing

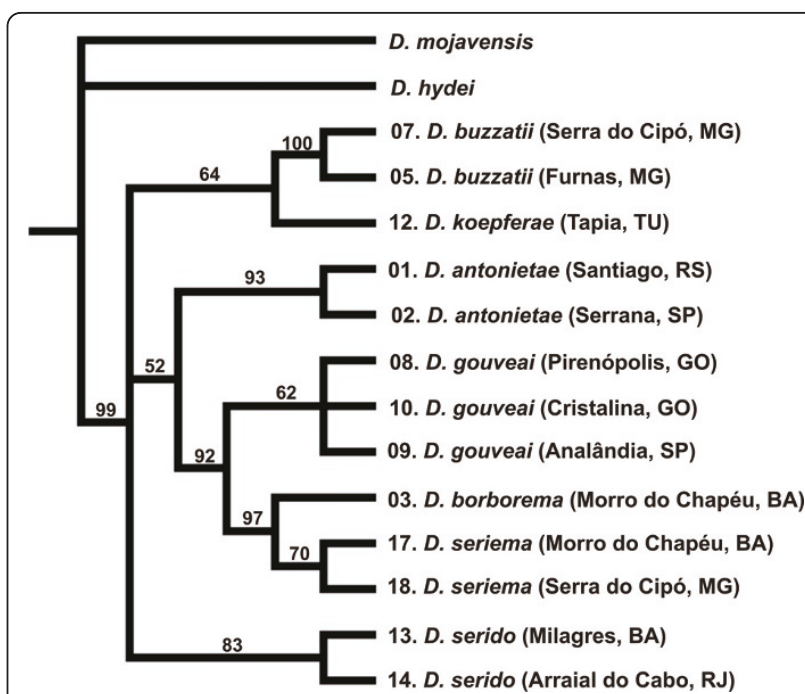

Figure 5 Strict consensus tree of six most parsimonious trees (Length $=166, \mathrm{Cl}=0.82 ; \mathrm{RI}=0.76$ ) of the populations/species of the $D$. buzzatii cluster plus two outgroup species $(D$. mojavensis and $D$. hydei) inferred from chromosomal inversions [41] and period gene data [44]. Bootstrap support (1,000 replicates and 100 random additions) is shown above the branches. Only bootstrap values above $50 \%$ are shown. The numbers before the species names represent the localities where the populations used for $\mathrm{CHC}$ analysis were collected. Only populations that had data for both $\mathrm{CHC}$ and per gene were used to reconstruct the phylogeny, i. e. 13 out of 18 populations (see Table 1).

populations of D. gouveai. Since polytomies had to be resolved prior to performing the character reconstruction analyses, these two trees were equivalent for character mapping. Trees 3 and 4 also had the same order of taxa observed for trees 1 and 2 and differed from them only in the arrangement of internal branches. Trees 5 and 6 differed from the first four trees by clustering $D$. serido populations in the same clade containing the D. buzzatii populations and D. koepferae rather than in a separate clade.

In the reconstructed phylogeny based on the populations/species of the D. buzzatii cluster plus the D. mojavensis cluster, significant phylogenetic signal was observed for female CV1 (Table 4) when linear parsimony (LP) (Additional File 2: Figure S2), squared change parsimony punctuated (SCPP) and the test of serial independence (TFSI) were used, but no correlation was observed when squared change parsimony gradual (SCPG) was used. For male CV1, all four methods yielded significant phylogenetic signal (Table 4). Female CV2 displayed significant phylogenetic signal only with TFSI and female and male CV5 were significant only with LP method. For CV2, CV3, and CV4, no concordance between $\mathrm{CHC}$ profiles and the phylogeny was detected with any of the three parsimony methods. Similar results were obtained with TFSI, except for 
Table 4 Analysis of congruence between the chromosomal inversion plus per gene phylogeny and CHC data.

\begin{tabular}{|c|c|c|c|c|c|c|c|c|c|c|c|}
\hline \multirow[b]{3}{*}{ Characters } & \multicolumn{9}{|c|}{ PARSIMONY METHODS } & \multicolumn{2}{|c|}{$\begin{array}{l}\text { TEST FOR SERIAL } \\
\text { INDEPENDENCY (TFSI) }\end{array}$} \\
\hline & \multicolumn{3}{|c|}{ Linear Parsimony (LP) } & \multicolumn{3}{|c|}{$\begin{array}{l}\text { Squared Change Parsimony } \\
\text { Gradual (SCPG) }\end{array}$} & \multicolumn{3}{|c|}{$\begin{array}{l}\text { Squared Change Parsimony } \\
\text { Punctuated (SCPP) }\end{array}$} & \multirow[b]{2}{*}{$\begin{array}{l}\text { Observed Mean C- } \\
\text { Statistics }\end{array}$} & \multirow[b]{2}{*}{$P$} \\
\hline & $\begin{array}{l}\text { Reference } \\
\text { Tree }\end{array}$ & $\begin{array}{l}\text { Random } \\
\text { Trees }\end{array}$ & $P$ & $\begin{array}{l}\text { Reference } \\
\text { Tree }\end{array}$ & $\begin{array}{l}\text { Random } \\
\text { Trees }\end{array}$ & $P$ & $\begin{array}{l}\text { Reference } \\
\text { Tree }\end{array}$ & $\begin{array}{l}\text { Random } \\
\text { Trees }\end{array}$ & $P$ & & \\
\hline $\begin{array}{l}\text { Female } \\
\text { CV1 }\end{array}$ & 26.91 & 37.14 & 0.0012 & 37.17 & 78.63 & 0.0921 & 105.88 & 166.56 & 0.0026 & 0.3615 & 0.0020 \\
\hline $\begin{array}{l}\text { Female } \\
\text { CV2 }\end{array}$ & 32.17 & 32.75 & 0.3317 & 94.71 & 75.49 & 0.7182 & 228.03 & 158.34 & 0.9553 & -0.3217 & 0.0090 \\
\hline $\begin{array}{l}\text { Female } \\
\text { CV3 }\end{array}$ & 27.47 & 30.34 & 0.1287 & 26.10 & 39.20 & 0.1756 & 69.06 & 82.77 & 0.1976 & 0.1094 & 0.2460 \\
\hline $\begin{array}{l}\text { Female } \\
\text { CV4 }\end{array}$ & 26.61 & 29.81 & 0.0931 & 31.77 & 42.13 & 0.3025 & 66.29 & 89.39 & 0.0683 & 0.1593 & 0.2210 \\
\hline $\begin{array}{l}\text { Female } \\
\text { CV5 }\end{array}$ & 26.31 & 37.30 & 0.0040 & 23.43 & 51.03 & 0.0306 & 59.80 & 108.28 & 0.0223 & 0.2981 & 0.0480 \\
\hline Male CV1 & 16.24 & 23.37 & 0.0004 & 11.88 & 28.88 & 0.0002 & 32.43 & 61.08 & 0.0004 & 0.447 & 0.0010 \\
\hline Male CV2 & 32.43 & 32.13 & 0.4783 & 83.85 & 69.03 & 0.6803 & 197.64 & 146.13 & 0.9652 & -0.2548 & 0.0490 \\
\hline Male CV3 & 29.20 & 30.75 & 0.2032 & 35.84 & 47.76 & 0.2850 & 91.14 & 101.18 & 0.2689 & 0.0579 & 0.2930 \\
\hline Male CV4 & 28.92 & 31.11 & 0.1142 & 53.11 & 56.40 & 0.4929 & 99.37 & 119.68 & 0.1340 & 0.0761 & 0.3000 \\
\hline Male CV5 & 27.39 & 36.75 & 0.0080 & 43.49 & 51.24 & 0.8830 & 75.87 & 108.81 & 0.0699 & 0.1669 & 0.1590 \\
\hline
\end{tabular}

The reconstructed phylogeny used in the character evolution analysis represents the first out of six most parsimonious trees and was based on 13 populations/ species of the $D$. buzzatii cluster (see Table 1) plus three species of the D. mojavensis cluster. CDF analysis was based on $21 \mathrm{CHC}$ peaks to generate the canonical variates (CVs). Three different parsimony methods were used in Mesquite [57]: linear parsimony (LP), squared-change parsimony assuming a gradual model of evolution (SCPG), and squared-change parsimony with a punctuated model of evolution (SCPP). In all three models, presence of phylogenetic signal for each character (i.e. female and male CVs) was assessed by comparing the mean parsimony character steps from the reference tree (as shown on Figure 6) with those of a population of random trees. Terminal taxa were reshuffled 10,000 times to generate the random trees. Phylogenetic signal was positive when the mean parsimony character steps for the reference tree were significantly smaller than the mean parsimony character steps for the random trees. See Additional File 2 : Figure S2 for details. The detection of phylogenetic signal was also examined with the test for serial independence (TFSI) run with 1,000 replicates using the program Phylogenetic Independence 2.0 [69]. P-values in bold represent significant values after false discovery rate (FDR) analysis. See Additional File 12: Table S8 for FDR calculations.

female CV2, which was positive for phylogenetic signal (Table 4). Figure 6A, B and 6C shows the first three female and male CVs mapped onto the phylogeny using the LP method. For CV1, the CHCs of the D. mojavensis cluster clearly differed from those of the $D$. buzzatii cluster (Figure 6A). Within the D. buzzatii cluster, female $D$. buzzatii and $D$. koepferae had very similar $\mathrm{CHC}$ profiles that were not shared among the other species, except for D. borborema. For males, D. buzzatii and $D$. koepferae also had similar profiles, but this similarity was also shared with other taxa, mainly with $D$. antonietae populations and D. serido from Arraial do Cabo. The most differentiated population in terms of $\mathrm{CHCs}$ was $D$. serido from Milagres, Bahia (Figure 3A and 4). No phylogenetic signal was observed for CV2 and $\mathrm{CV} 3$ as indicated by the somewhat random distributions of $\mathrm{CHC}$ profiles across the tree (Figure 6B, C). For CV2, another D. serido population from Arraial do Cabo, Rio de Janeiro had the most divergent $\mathrm{CHC}$ profile (Figure 6B) whereas for CV3, D. borborema from Morro do Chapéu, Bahia was the most divergent group (Figure 6C). The influence of sex on $\mathrm{CHC}$ variation was diminished because we included male and female $\mathrm{CHC}$ data for each population/species to generate common canonical variables all on the same CDF scales.
In order to dissect these patterns of covariation further, we evaluated the loadings of each $\mathrm{CHC}$ on the canonical variates. Almost all individual $\mathrm{CHCs}$ were significantly correlated with each of the first five CVs (Table 5). For CV1, all CHC peaks significantly contributed to the variation, except for $\mathrm{C}_{32.56}$, but three $\mathrm{CHCs}$ with the highest loadings, $\mathrm{C}_{33 \mathrm{br} 3}, \mathrm{C}_{32.47}$, and $\mathrm{C}_{35 \text { ene3 } 3}$ and to a lesser extent two $C_{35}$ components, $C_{35 \text { ene3 }}$ and $\mathrm{C}_{34.66}$, best discriminated among these populations. Only two of these components, $\mathrm{C}_{32.47}$ and $\mathrm{C}_{34.66}$, represented significant proportions of total $\mathrm{CHCs}$ or were "major peaks" in these species suggesting that even relatively "minor" CHC components were responsible for these species differences that resulted in the detection of phylogenetic signal in $\mathrm{CHC}$ differentiation and evolution. Similar results were observed for CV2, CV3, CV4, and CV5, where most of the $\mathrm{CHC}$ components were significantly correlated with the CVs. When sex was considered as a variable in the model, the percentage of the variance explained by the first five CVs increased from $72 \%$ to $81 \%$ (results not shown), with the highest difference found in CV1, from $17 \%$ to $22 \%$.

Because presence of phylogenetic signal, especially for $\mathrm{CV} 1$, seemed to be related to $\mathrm{CHC}$ differences between both clusters, we performed an analysis without the $D$. 


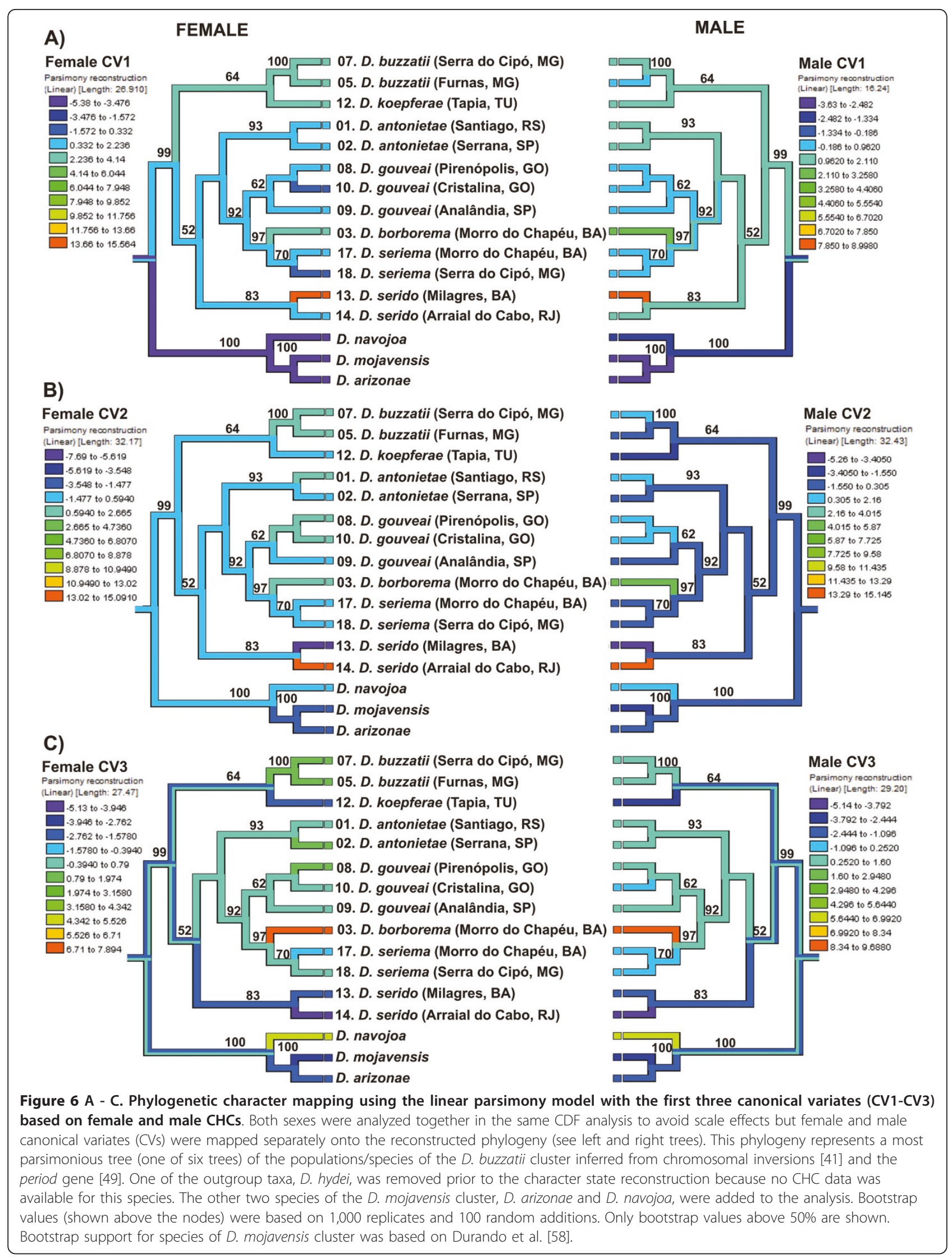


Table 5 The first five canonical variates based on the total canonical structure of 13 populations/species of the $D$. buzzatii cluster plus the three species of the $D$. mojavensis cluster.

\begin{tabular}{|c|c|c|c|c|c|c|}
\hline $\begin{array}{l}\text { Carbon } \\
\text { Number }\end{array}$ & $\begin{array}{c}\text { CHC } \\
\text { Peak }^{+}\end{array}$ & $\begin{array}{l}\text { CV1 } \\
(17 \%)\end{array}$ & $\begin{array}{l}\text { CV2 } \\
(17 \%)\end{array}$ & $\begin{array}{l}\text { CV3 } \\
(14 \%)\end{array}$ & $\begin{array}{l}\text { CV4 } \\
(13 \%)\end{array}$ & $\begin{array}{l}\text { CV5 } \\
(11 \%)\end{array}$ \\
\hline 29 & $C_{28.65}$ & $-0.181^{* * *}$ & $-0.381^{* * * *}$ & $-0.573^{* * * *}$ & $0.192^{* * *}$ & $0.006 \mathrm{~ns}$ \\
\hline \multirow[t]{3}{*}{31} & $C_{30.65}$ & $-0.379^{* * * *}$ & $-0.453^{* * * *}$ & 0.102 ns & $-0.356^{* * * *}$ & $0.349^{* * * *}$ \\
\hline & $C_{30.78}$ & $-0.291^{* * * *}$ & 0.100 ns & $-0.199 * * *$ & $-0.180^{* * *}$ & $-0.422^{* * * *}$ \\
\hline & $C_{30.83}$ & $0.153^{* *}$ & $0.811^{* * * *}$ & $-0.361^{* * * *}$ & $-0.226^{* * * *}$ & $0.127^{*}$ \\
\hline \multirow[t]{8}{*}{33} & $C_{33 \mathrm{br} 2}$ & $-0.607^{* * * *}$ & $-0.283^{* * * *}$ & $-0.071 \mathrm{~ns}$ & $-0.028 \mathrm{~ns}$ & $0.358^{* * * *}$ \\
\hline & $C_{33 \mathrm{br} 3}$ & $0.871^{* * * *}$ & $-0.341^{* * * *}$ & $-0.142^{* *}$ & $-0.140^{* *}$ & 0.087 ns \\
\hline & $C_{32.47}$ & $-0.675^{* * * *}$ & $-0.332^{* * * *}$ & $-0.198^{* * *}$ & -0.053 ns & $0.050 \mathrm{~ns}$ \\
\hline & $C_{32.56}$ & $-0.042 \mathrm{~ns}$ & $-0.041 \mathrm{~ns}$ & $0.677^{* * * *}$ & $-0.663^{* * * *}$ & $0.093 \mathrm{~ns}$ \\
\hline & $C_{32.63}$ & $-0.146^{* *}$ & $-0.333^{* * * *}$ & $-0.425^{* * * *}$ & $0.131^{*}$ & $-0.065 \mathrm{~ns}$ \\
\hline & $C_{32.70}$ & $0.323^{* * * *}$ & $-0.382^{* * * *}$ & $-0.205^{* * * *}$ & $-0.264^{* * * *}$ & $-0.374 * * * *$ \\
\hline & $C_{32.79}$ & $0.125^{*}$ & $0.111^{*}$ & $-0.075 \mathrm{~ns}$ & $-0.130^{*}$ & $-0.665^{* * * *}$ \\
\hline & $C_{32.86}$ & $0.281^{* * * *}$ & $0.820^{* * * *}$ & $-0.307^{* * * *}$ & $-0.176^{* * *}$ & $-0.062 \mathrm{~ns}$ \\
\hline \multirow[t]{6}{*}{35} & $C_{35 e n e 1}$ & $-0.375^{* * * *}$ & $-0.220^{* * * *}$ & $0.189^{* * *}$ & $-0.206^{* * * *}$ & $0.405^{* * * *}$ \\
\hline & $C_{35 e n e 2}$ & $-0.520^{* * * *}$ & $-0.203^{* * * *}$ & $0.235^{* * * *}$ & $-0.115^{*}$ & $0.360^{* * * *}$ \\
\hline & $C_{35 \text { ene3 }}$ & $0.661^{* * * *}$ & -0.002 ns & $0.196^{* * *}$ & $0.359 * * * *$ & $-0.215^{* * * *}$ \\
\hline & $C_{34.59}$ & $-0.484^{* * * *}$ & $-0.271^{* * * *}$ & $-0.291 * * * *$ & 0.088 ns & $0.213^{* * * *}$ \\
\hline & $C_{34.66}$ & $-0.557^{* * * *}$ & $-0.366^{* * * *}$ & -0.017 ns & $-0.231^{* * * *}$ & $0.359^{* * * *}$ \\
\hline & $C_{34.79}$ & $0.504^{* * * *}$ & $0.001 \mathrm{~ns}$ & $0.158^{* *}$ & $0.224^{* * * *}$ & $-0.355^{* * * *}$ \\
\hline \multirow[t]{3}{*}{37} & $C_{37}$ & $-0.421^{* * * *}$ & $-0.234^{* * * *}$ & $-0.236^{* * * *}$ & $0.151^{* *}$ & $0.221^{* * * *}$ \\
\hline & $C_{36.5}$ & $-0.240^{* * * *}$ & $-0.042 \mathrm{~ns}$ & $0.423^{* * * *}$ & $0.409^{* * * *}$ & $0.485^{* * * *}$ \\
\hline & $C_{36.7}$ & $0.210^{* * * *}$ & $0.152^{* *}$ & $0.443^{* * * *}$ & $0.705^{* * * *}$ & $0.229^{* * * *}$ \\
\hline
\end{tabular}

Both sexes were run together in the same CDF analysis to avoid scale effects but mapped separated onto the reconstructed phylogeny (see Figure 6). Values in parenthesis represent the percentage of variance explained by each CV. Statistical significance of Pearson correlation coefficients between the original variables and canonical discriminant function loadings are indicated.

${ }^{+}$Equivalent chainlengths of each hydrocarbon as defined in Table 2.

ns $=$ not significant. ${ }^{*} P \leq 0.05,{ }^{* *} P \leq 0.01,{ }^{* * *} P \leq 0.01,{ }^{* * * *} P \leq 0.0001$.

mojavensis cluster in order to test whether phylogenetic signal would be present in the $D$. buzzatii cluster only. In the absence of $D$. mojavensis cluster, CV1 did not display positive phylogenetic signal (Additional File 9: Table S5). However, positive phylogenetic signal was detected for female CV3 and/or CV4 and male CV4 and CV5 (Additional File 9: Table S5) illustrating that positive phylogenetic signal for different covarying groups of CHCs was present in the D. buzzatii cluster even in the absence of an outgroup.

Because D. serido populations exhibited such high within-species $\mathrm{CHC}$ divergence (Figure 3A, B), we also considered the possibility that $D$. serido $\mathrm{CHCs}$ may have influenced the character mapping results. To test this hypothesis, we repeated the CDF analysis (Additional File 10: Table S6) and reconstructed the phylogeny without the two $D$. serido populations. In the absence of $D$. serido, male and female CV1 displayed positive phylogenetic signal with all four methods. However, as mentioned above, presence of phylogenetic signal for CV1 was influenced by including the $D$. mojavensis cluster. More strikingly was the fact that without the $D$. serido populations, all three parsimony methods (except for male SCPG) and TFSI had three or four CVs that tested positive for phylogenetic signal (Additional File 11: Table S7). Thus, the exclusion of the two rather discordant $D$. serido populations had a huge influence on our ability to detect phylogenetic signal in the differentiation of D. buzzatii cluster CHCs.

\section{Discussion}

Comparative analysis of quantitative variation in $\mathrm{CHC}$ profiles of the $D$. buzzatii species cluster revealed that $\mathrm{CHC}$ evolution has been somewhat conserved and associated with the evolutionary divergence of these species. Thus, CHC differentiation among these populations has not evolved so quickly as to erase evidence of phylogenetic affinity suggesting that variation in $\mathrm{CHCs}$ in this group of Drosophila can be predicted, to some extent, by species ancestry. Here, a key observation was the degree of CHC chemical conservation between the $D$. buzzatii and D. mojavensis clusters (Table 2) where most molecular structures, retention times, and carbon chainlengths were conserved, but species-specific $\mathrm{CHC}$ amounts varied quantitatively. The $D$. mojavensis cluster is also part of the mulleri complex, but is endemic to North America [59,72,73]. As these species groups are restricted to different continents and diverged ca 10-15 mya [74,75], CHC biosynthesis and expression have been conserved over a large portion of the D. repleta group phylogeny. The most conserved chemical compounds were 2-methyloctacosane $\left(2-\mathrm{MeC}_{28}\right)$ and 2-methyltriacontane $\left(2-\mathrm{MeC}_{30}\right)$. These two compounds are not only shared within and between both clusters but are also found in a variety of other insect species [76]. In retrospect, such conserved CHCs may not be surprising, but few attempts have been made to assess broad-scale variation in CHCs in groups of related species. Thus, CHC evolution in these D. repleta group species has a significant phylogenetic component based on a core group of $C_{29}, C_{31}, C_{33}, C_{35}, C_{37}$ and $C_{39}$ hydrocarbons (Additional File 3: Figure S3) with additional species and population-specific variations on this theme.

The multiple functional roles for insect cuticular hydrocarbons has been appreciated for some time [77]. In arthropods with longer chain length $\mathrm{CHCs}$ ( $>20$ carbon atoms), effects of desiccation are reduced because longer $\mathrm{CHCs}$ have higher melting temperatures [78,79], consistent with observations that xeric adapted Drosophila species exhibit longer chain length $\mathrm{CHCs}$ than mesic species [80]. Although saturated compounds, $n$-alkanes, provide increased protection against desiccation, branched and unsaturated compounds decrease 
melting temperatures and can cause increased rates of water loss across insect epicuticles [78]. In Drosophila, alkenes and alkadienes have pheromonal activity in a number of species $[14,81-84]$. In experimental populations of $D$. melanogaster that responded to increased desiccation conditions, $\mathrm{CHC}$ differences did evolve, but there were no associated changes in sexual isolation suggesting that $\mathrm{CHCs}$ involved in desiccation resistance were different from those used for mate choice [85]. In other insects like paper wasps [86] and honeybees [87], branched alkanes and/or alkenes are more easily identified by other individuals than linear alkanes and therefore serve as recognition cues while $n$-alkanes function primarily to reduce water loss. Given the conservation of CHC compounds in the desert-adapted D. buzzatii and $D$. mojavensis species groups, significant sexual dimorphism in $\mathrm{CHC}$ profiles (Table 3), and the presence of branched and unsaturated molecules in the $\mathrm{CHCs}$ of all of these species, we expect that $D$. buzzatii cluster CHCs serve as both physiological mechanisms to control transcuticular water flux as well as in chemical communication, i.e. mate recognition. Nevertheless, the role of $\mathrm{CHCs}$ as pheromones has yet to be confirmed in the D. buzzatii cluster. Preliminary results revealed undetectable pheromonal activity in $\mathrm{CHC}$ perfuming experiments with $D$. seriema and $D$. buzzatii even though significant amounts of $\mathrm{CHCs}$ were transferred between males (Oliveira et. al., unpubl. data). However, we initially chose these species for perfuming studies because of the ability to detect $\mathrm{CHC}$ transfers. This result may not be representative of other, more closely related species in the cluster because $D$. seriema and $D$. buzzatii were so reproductively divergent (in mate choice trials, Oliveira et. al., unpubl. data) that alterations in $\mathrm{CHCs}$ had little effect despite the significant $\mathrm{CHC}$ differences between them. Further perfuming trials with all $D$. buzzatii cluster species are clearly needed.

The detection of positive phylogenetic signal using the three different data sets: (1) D. buzzatii $+D$. mojavensis cluster; (2) D. buzzatii cluster; and (3) D. buzzatii cluster (without $D$. serido populations) $+D$. mojavensis cluster (Table 4, Additional Files 9 and 11, respectively) supports the hypothesis that phylogenetic signal was strong enough to be detected by different methods independent of their assumptions. Moreover, positive phylogenetic signal was observed when just the D. buzzatii cluster species were used supporting that some $\mathrm{CHCs}$ were conserved in the cluster. These results were even more robust when the divergent $D$. serido populations were removed from the analysis. We hypothesize that CVs that were weakly correlated with the phylogeny, mainly $\mathrm{CV} 2$, were influenced by $\mathrm{CHCs}$ that may be responding to the ambient environment or other forces, i.e. these are traits involved in mate recognition like courtship songs, pheromones, or coloration that should evolve more rapidly due to sexual or stabilizing selection [88-91].

Contrasting results have been reported regarding the presence of phylogenetic signal in studies of character evolution that have implicated $\mathrm{CHCs}$ and other volatile compounds in mate and/or species recognition. For example, Jallon and David [13] concluded that "Hydrocarbon variations do not match the phylogeny" in eight species of the D. melanogaster group. Symonds and Elgar [92] reported little association between aggregation pheromone composition and phylogenetic relationships in bark beetles since closely related species were as different, if not more so, than more distantly related species. Conversely, Symonds and Wertheim [93] found that more closely related Drosophila species had more chemically similar aggregation pheromones and concluded that there was a positive relationship between phylogenetic distance and pheromone differentiation. Cuticular hydrocarbons in pine engraver beetles have been used to identify different species and thus have systematic value [94]. Some phylogenetic trends in species-specific $\mathrm{CHCs}$ were also reported in Hawaiian swordtail crickets [11]. However, known phylogenetic relationships among 78 ant species in five subfamilies showed "no similarity" to cuticular hydrocarbon differences based on chemical structures [95]. Male courtship songs were homoplasic in the Drosophila willistoni species complex [88], showed evidence of diversification, character loss, and reversal in the D. repleta group [33], and converged in green lacewings [96]. In birds, sexually selected traits like male plumage and bower characters exhibited low phylogenetic signal $[97,98]$, while male songs were more conserved [99]. We suggest that phylogenetic diversification of insect $\mathrm{CHCs}$ may be more conservative than courtship songs or avian plumage characteristics because the complex underlying biochemical and physiological machinery required to synthesize and express CHCs in arthropods $[9,100,101]$ may be more conserved than in other traits. Thus, similarity in cuticular hydrocarbon profiles among species may represent a phylogenetic constraint due to their mode of production. Certainly, more comparative studies involving mating signals will be necessary to determine whether the presence of phylogenetic signal is a rule or an exception for pheromonal or behavioral traits.

\section{Evolution of the $D$. buzzatii cluster and CHCs}

Attempts to resolve a phylogeny using the mtDNA data [44] failed to resolve all species into individual evolutionary lineages. Specifically, D. gouveai, D. serido, and D. seriema show substantial geographic variation and considerable phylogenetic incongruence (Additional File 1: Figure S1). Incomplete lineage sorting or 
hybridization could be responsible, as well as natural selection on mtDNA function [102]. Phylogenetic reconstruction based on the nuclear period (per) gene by Franco et al. [46] resolved the relationships among $D$. gouveai, D. borborema and D. seriema (Figure 5). Although per grouped populations of $D$. serido together, they were not placed as a sister taxa of $D$. antonietae, as predicted by chromosomal inversion data (Figure 2). Therefore, the position of "D. serido" has yet to be resolved.

The large and very significant intraspecific differences in D. serido CHCs (Figure 3A) does not suggest a gradual model of $\mathrm{CHC}$ evolution, but were consistent with previously described differentiation between populations that inhabit northeastern Brazil in the caatinga (e.g. Milagres, Bahia) and those from the east coast of Brazil (e.g. Mucuri, Bahia and Arraial do Cabo, Rio de Janeiro, see Figure 1). The observation that the $\mathrm{CHCs}$ of the coastal $D$. serido population from Macaé, Rio de Janeiro did not match this pattern of differentiation further suggests that this stock was contaminated (see results for details). Here, the scale of intraspecific $\mathrm{CHC}$ variation was greater than interspecific variation for the remaining six species, and included multiple $\mathrm{CHC}$ components (Figure 4). Genetic divergence between populations of $D$. serido in these regions includes mtDNA haplotype differentiation [44], cytological differences, amounts of heterochromatin in metaphase chromosomes [103], and frequency differences of polymorphic inversions $[41,104]$. These observations together with our results showing large intraspecific $\mathrm{CHC}$ differences strongly suggest the presence of several more cryptic species in this group.

\section{Conclusions}

The evolution of phenotypes and how they are shaped by phylogenetic history is a long-standing issue [1]. Our comparative approach revealed that $\mathrm{CHC}$ compounds were highly conserved among species. Quantitative differences in $\mathrm{CHC}$ profiles were more prominent yet $\mathrm{CHCs}$ were species-, population-, and sex-specific. The evolution of $\mathrm{CHCs}$ was not homogeneous as some peaks were more conserved and retained phylogenetic signal while others seemed to be evolving faster. Comparative approaches to understanding phenotypes such as $\mathrm{CHCs}$ with multiple functions and courtship songs in Drosophila have provided some insight into the patterns of trait evolution for phenotypes likely associated with mating success and reproductive isolation, as well as the challenges of xeric environments caused by desiccation and cuticular water loss. For understanding of $\mathrm{CHC}$ evolution, future analyses of multiple phenotypes in such groups will be necessary to evaluate whether $\mathrm{CHC}$ components influence water balance and/or have pheromonal activity and to determine how the type and quantity of these compounds evolve during the diversification of populations and species.

\section{Additional material}

\begin{abstract}
Additional file 1: Figure S1. Strict consensus trees of the $D$. buzzatii cluster. A) Phylogeny inferred from mtDNA COI data. B) Phylogeny based on chromosomal inversions + mtDNA + period gene. Bootstrap support (1,000 replicates and 100 random additions) is shown above the branches. Only bootstrap values above $50 \%$ are shown. See Figure 5 for strict consensus tree inferred from chromosomal inversions + period gene.

Additional file 2: Figure S2. Bar graphs of random distributions generated by the shuffle option in Mesquite using the Linear Parsimony Method. (A) Data showing presence of phylogenetic signal. The number of parsimony character steps for the reference tree (see Figure 6 A) was significantly smaller, i.e. fell on the left side of the distribution, than the number of parsimony character steps for the trees with reshuffled taxa. (B) Data exhibiting lack of phylogenetic signal, i.e. random association between $\mathrm{CHCs}$ and the phylogeny (see Figure 6B) where the number of parsimony character steps for the reference tree fell within the $95 \%$ confidence interval. If the parsimony character steps for the reference tree fell on the extreme right of the distribution (not observed with our data) that would imply that $\mathrm{CHC}$ distributions were less conserved than by chance alone (e. g. due to character displacement). Vertical red lines represent $95 \%$ confidence intervals and green lines denote the mean number of parsimony character steps for the trees with reshuffled taxa. Red arrows represent the parsimony character steps for the reference tree.
\end{abstract}

Additional file 3: Figure S3. Gas chromatograms showing representative species-specific $\mathrm{CHC}$ profiles of males and females in the $D$. buzzatii species cluster.

Additional file 4: Table S1. CHC amounts for the 12 major hydrocarbon peaks, out of 36 used to calculate total CHCs (ng/fly), found in the $D$. buzzatii species cluster. Equivalent chain lengths were used instead of the hydrocarbon names, because of the qualitative differences found among the different species. See Table 2 for the corresponding hydrocarbon names. $\mathrm{F}=$ female; $\mathrm{M}=$ male.

Additional file 5: Table S2. The first five canonical variates (CVs) based on the total canonical structure of 18 populations/species of the $D$. buzzatii cluster. CDF analysis included sex as a variable in the model. Values in parentheses represent the percent of total variance explained by each CV. Statistical significance of Pearson correlation coefficients between the original variables and canonical discriminant function loadings are indicated.

Additional file 6: Table S3. The first five canonical variates (CVs) based on the total canonical structure of 14 populations/species of the $D$. buzzatii cluster after deleting the four $D$. serido populations. CDF analysis included sex as a variable in the model. Values in parentheses represent the percent of total variance explained by each CV. Statistical significance of Pearson correlation coefficients between the original variables and canonical discriminant function loadings are indicated.

Additional file 7: Table S4. Results of the stepwise discriminant analysis based on 18 populations/species of the $D$. buzzatii cluster (see Table 1). The forward elimination method yielded the same results as the backward method, but the latter could not be used because all variables significantly discriminated between populations/species.

Additional file 8: Figure S4. The six most parsimonious trees recovered based on chromosomal inversions and per gene sequence data. Bootstrap support (1,000 replicates and 100 random additions) is shown above the branches. Only bootstrap values above $50 \%$ are shown.

Additional file 9: Table S5. Analysis of congruence between the chromosomal inversion plus per gene phylogeny and CHC data. The 
reconstructed phylogeny used in the character evolution analysis represents the first out of six most parsimonious trees and was based on 13 populations/species of the $D$. buzzatii cluster. The species of the $D$. mojavensis cluster were not included in this analysis. CDF analysis was based on $21 \mathrm{CHC}$ peaks to generate the canonical variates (CVs). $\mathrm{LP}=$ linear parsimony; SCPG = squared-change parsimony gradual; and SCPP $=$ squared-change parsimony punctuated. See Table 4 for details. $P$ values in bold represent significant values after false discovery rate (FDR) analysis. See Additional File 12: Table 58 for FDR calculations.

Additional file 10: Table S6. The first five canonical variates based on the total canonical structure of 11 populations/species of the $D$. buzzatii cluster (after deleting the two $D$. serido populations) plus the three species of the $D$. mojavensis cluster used in the phylogenetic reconstruction. Both sexes were analyzed together in the same CDF analysis to avoid scale effects, but were mapped separately onto the phylogeny (see Figure 6). Values in parentheses represent the percent of the total variance explained by each CV. Statistical significance of Pearson correlation coefficients between the original variables and canonical discriminant function loadings is indicated.

Additional file 11: Table S7. Analysis of congruence between the chromosomal inversion + per gene phylogeny and CHC data. The reconstructed phylogeny used in the character evolution analysis represents the first out of six most parsimonious trees and was based on 11 populations/species of the $D$. buzzatii cluster, after deleting the two $D$. serido populations, plus three species of the $D$. mojavensis cluster. $L P=$ linear parsimony; SCPG = squared-change parsimony gradual; and SCPP = squared-change parsimony punctuated. Besides the three parsimony methods, the detection of phylogenetic signal was also examined with the test for serial independence (TFSI) (run with 1,000 replicates) using the program Phylogenetic Independence 2.0 [69]. See Table 4 for details. $P$-values in bold represent significant values after false discovery rate (FDR) analysis. See Additional File 12: Table 58 for FDR calculations.

Additional file 12: Table S8. False discovery rate (FDR) analyses $[70,71]$ of the statistical results from the character reconstruction analyses using the three parsimony methods and the test for serial independence. FDR analyses were calculated for the three different data sets used to reconstruct the phylogeny: A) 13 populations/species of the D. buzzatii cluster plus the three species of the D. mojavensis cluster; B)

13 populations/species of the D. buzzatii cluster (no outgroups); and C)

11 populations/species of the $D$. buzzatii cluster (no D. serido

populations) plus the three species of the D. mojavensis cluster. For each of these three data sets, significant values after FDR analysis are shown in bold in Table 4, Additional File 9: Table S5 and Additional File 11: Table S7, respectively. FDR analyses were calculated separated for females and males. Probabilities are given in increasing order.

\section{Acknowledgements}

We thank G. Almeida and A. Tripodi for help with the GC, P.R. Epifânio for technical assistance, and W. Maddison and M. Laurin for help with Mesquite. F.F. Franco and A.L.H. Esquicero assisted with field collection of cactus and flies. WJE and CCO thank L. Jackson for revealing the secrets of Drosophila hydrocarbon GCMS and for his hospitality in Bozeman. We also thank M.G. Ritchie and D.C.S.G. Oliveira for their comments on an earlier version of the manuscript and three anonymous reviewers for valuable criticisms and insights. Funding was provided by a supplement to National Science Foundation DEB-0211125 to WJE, a Dissertation Research Award from the J. William Fulbright College of Arts \& Sciences, University of Arkansas to CCO, and grants from FAPESP, CNPq and USP to MHM and FMS

\section{Author details}

'Program in Ecology and Evolutionary Biology, Department of Biological Sciences, SCEN 632, University of Arkansas, Fayetteville, AR 72701, USA. ${ }^{2}$ School of Biological Sciences, 302 Manter Hall, University of Nebraska, Lincoln, NE 68588, USA. ${ }^{3}$ Departamento de Biologia, Faculdade de Filosofia, Ciências e Letras de Ribeirão Preto, Universidade de São Paulo, Av. dos Bandeirantes, 3900 Ribeirão Preto-SP, 14040-901, Brazil. ${ }^{4}$ Departamento de Genética, Faculdade de Medicina de Ribeirão Preto, Universidade de São
Paulo, Av. dos Bandeirantes, 3900 Ribeirão Preto-SP, 14049-900, Brazil. ${ }^{5}$ Chemistry and Biochemistry Department, Montana State University, Bozeman, MT 59717, USA

\section{Authors' contributions}

CCO designed and conducted the experiments and performed statistical analyses. WJE assisted with the design and coordination of the study. LLJ carried out and analyzed the gas chromatography-mass spectrometry data. MHM and FMS helped with fly collection and coordination of the study. CCO and WJE wrote the manuscript. All authors read and approved the final manuscript.

Received: 30 November 2010 Accepted: 23 June 2011

Published: 23 June 2011

\section{References}

1. Harvey PH, Pagel MD: The comparative method in evolutionary biology. New York: Oxford Univ. Press; 1991.

2. Blomberg SP, Garland T Jr, Ives AR: Testing for phylogenetic signal in comparative data: Behavioral traits are more labile. Evolution 2003, 57(4):717-745.

3. Wimberger PH, de Queiroz A: Comparing behavioral and morphological characters as indicators of phylogeny. In Phylogenies and the Comparative Method in Animal Behavior. Edited by: Martins EP. New York: Oxford University Press; 1996:206-233.

4. Rendall D, Di Fiore A: Homoplasy, homology, and the perceived special status of behavior in evolution. J Hum Evol 2007, 52(5):504-521.

5. Duckworth RA: The role of behavior in evolution: a search for mechanism. Evol Ecol 2009, 23:513-531.

6. Blows MW, Allen RA: Levels of mate recognition within and between two Drosophila species and their hybrids. Am Nat 1998, 152:826-837.

7. Etges WJ, Jackson LL: Premating isolation is determined by larval rearing substrates in cactophilic Drosophila mojavensis. VI. Epicuticular hydrocarbon variation in Drosophila mojavensis cluster species. $J$ Chem Ecol 2001, 27:2125-2149.

8. Tompkins L, McRobert SP, Kaneshiro KY: Chemical communication in Hawaiian Drosophila. Evolution 1993, 47:1407-1419.

9. Howard RW, Blomquist GJ: Ecological, Behavioral, and Biochemical aspects of insect hydrocarbons. Annu Rev Entomol 2005, 50:371-393.

10. Smadja C, Butlin RK: On the scent of speciation: the chemosensory system and its role in premating isolation. Heredity 2008, 102:77-97.

11. Mullen SP, Mendelson TC, Schal C, Shaw KL: Rapid evolution of cuticular hydrocarbons in a species radiation of acoustically diverse Hawaiian crickets (Gryllidae:Trigonidiinae Laupala). Evolution 2007, 61:223-231.

12. Peterson MA, Dobler S, Larson EL, Juárez D, Schlarbaum T, Monsen KJ, Francke W: Profiles of cuticular hydrocarbons mediate male mate choice and sexual isolation between hybridizing Chrysochus (Coleoptera: Chrysomelidae). Chemoecology 2007, 17:87-96.

13. Jallon J-M, David JR: Variations in cuticular hydrocarbons among the eight species of the Drosophila melanogaster subgroup. Evolution 1987, 41:294-302.

14. Coyne JA, Crittenden AP, Mah K: Genetics of a pheromonal difference contributing to reproductive isolation in Drosophila. Science 1994, 265:1461-1464

15. Ferveur JF, Cobb M, Boukella H, Jallon JM: World-wide variation in Drosophila melanogaster sex pheromone: behavioural effects, genetic bases and potential evolutionary consequences. Genetica 1996, 97(1):73-80.

16. Coyne JA, Oyama R: Localization of pheromonal sexual dimorphism in Drosophila melanogaster and its effect on sexual isolation. Proc Natl Acad SCi USA 1995, 92:9505-9509.

17. Etges WJ, Ahrens MA: Premating isolation is determined by larval rearing substrates in cactophilic Drosophila mojavensis. V. Deep geographic variation in epicuticular hydrocarbons among isolated populations. Am Nat 2001, 158:585-598.

18. Higgie M, Blows MW: Are traits that experience reinforcement also under sexual selection? Am Nat 2007, 170:409-420.

19. Gibbs AG: Water-proofing properties of cuticular lipids. Am Zool 1998, 38(3):471-482.

20. Gibbs AG, Matzkin LM: Evolution of water balance in the genus Drosophila. J Exp Biol 2001, 204:2331-2338. 
21. Gibbs AG, Perkins MC, Markow TA: No place to hide: microclimates of Sonoran Desert Drosophila. J Therm Biol 2003, 28(5):353-362.

22. Symonds MRE, Elgar MA: The evolution of pheromone diversity. Trends Ecol Evol 2008, 23(4):220-228.

23. Ferveur JF: Cuticular hydrocarbons: their evolution and roles in Drosophila pheromonal communication. Behav Genet 2005, 35(3):279-295

24. Toolson EC, Markow TA, Jackson LL, Howard RW: Epicuticular hydrocarbon composition of wild and laboratory-reared Drosophila mojavensis Patterson and Crow (Diptera: Drosophilidae). Ann Entomol Soc Am 1990, 83(6):1165-1176.

25. Bartelt RJ, Armold MT, Schaner AM, Jackson LL: Comparative analysis of cuticular hydrocarbons in the Drosophila virilis species group. Comp Biochem Physiol 1986, , 83B: 731-742.

26. Stennett MD, Etges WJ: Premating isolation is determined by larval rearing substrates in cactophilic Drosophila mojavensis. III. Epicuticular hydrocarbon variation is determined by use of different host plants in Drosophila mojavensis and Drosophila arizonae. J Chem Ecol 1997, 23:2803-2824.

27. Etges WJ: Premating isolation is determined by larval rearing substrates in cactophilic Drosophila mojavensis. Evolution 1992, 46:1945-1950.

28. Petfield D, Chenoweth SF, Rundle HD, Blows MW: Genetic variance in female condition predicts indirect genetic variance in male sexual display traits. Proc Natl Acad Sci USA 2005, 102(17):6045-6050.

29. Krupp JJ, Kent C, Billeter J-C, Azanchi R, So AKC, Schonfeld JA, Smith BP, Lucas C, Levine JD: Social experience modifies pheromone expression and mating behavior in male Drosophila melanogaster. Curr Biol 2008, 18(18):1373-1383.

30. Etges WJ, Oliveira CC, Ritchie MG, Noor MAF: Genetics of incipient speciation in Drosophila mojavensis. II. Host plants and mating status influence cuticular hydrocarbon QTL expression and G $\times$ E interactions. Evolution 2009, 63:1712-1730

31. Everaerts C, Farine J-P, Cobb M, Ferveur J-F: Drosophila cuticular hydrocarbons revisited: mating status alters cuticular profiles. PLOS ONE 2010, 5(3):e9607.

32. Coyne JA, Orr HA: Speciation. Sunderland, MA: Sinauer; 2004

33. Etges WJ: Divergence in mate choice systems: does evolution play by rules? Genetica 2002, 116(2-3):151-166.

34. Manfrin MH, Sene FM: Cactophilic Drosophila in South America: A model for evolutionary studies. Genetica 2006, 126(1-2):57-75.

35. Patterson JT, Wheeler MR: Description of new species of the subgenera Hirtodrosophila and Drosophila. University of Texas Publication 1942, 4213:67-109.

36. Vilela CR, Sene FM: Two new Neotropical species of the repleta group of the genus Drosophila (Diptera, Drosophilidae). Pap Avulsos Zool 1977, 30:295-299.

37. Fontdevila A, Pla C, Hasson E, Wasserman M, Sanchez A, Naveira H, Ruiz A Drosophila koepferae: A new member of the Drosophila serido (Diptera Drosophilidae) superspecies taxon. Ann Entomol Soc Am 1988, 81:380-385.

38. Tidon-Sklorz R, Sene FM: Drosophila seriema: A new member of the Drosophila serido (Diptera, Drosophilidae) superspecies taxon. Ann Entomol Soc Am 1995, 88(1):1139-1142.

39. Tidon-Sklorz R, Sene FM: Two new species of the Drosophila serido sibling set (Diptera, Drosophilidae). Iheringia Ser Zool 2001, 90:141-146.

40. Ruiz A, Wasserman M: Evolutionary cytogenetics of the Drosophila buzzatii species complex. Heredity 1993, 70:582-596.

41. Ruiz A, Cansian AM, Kuhn GCS, Alves MAR, Sene FM: The Drosophila serido speciation puzzle: putting new pieces together. Genetica 2000, 108:217-227.

42. O'Grady PM, Baker R, Durando CM, Etges WJ, DeSalle R: Polytene chromosomes as indicators of phylogeny in several species groups of Drosophila. BMC Evol Biol 2001, 2001:1-6.

43. Krimbas CB, Powell JR: Drosophila Inversion Polymorphism. Boca Raton: CRC Press, Inc; 1992

44. Manfrin MH, de Brito ROA, Sene FM: Systematics and evolution of the Drosophila buzzatii (Diptera: Drosophilidae) cluster using mtDNA. Ann Entomol Soc Am 2001, 94(3):333-346.

45. de Brito RA, Manfrin MH, Sene FM: Mitochondrial DNA phylogeography of Brazilian populations of Drosophila buzzatii. Genet Mol Biol 2002, 25(2):161-171

46. Franco FF, Silva-Bernardi ECC, Sene FM, Hasson ER, Manfrin MH: Intra- and interspecific divergence in the nuclear sequences of the clock gene period in species of the Drosophila buzzatii cluster. J Zool Syst Evol Res 2010, 48(4):322-331.

47. Sene FM, Pereira MAQR, Vilela CR: Evolutionary aspects of cactus breeding Drosophila in South America. In Ecological Genetics and Evolution The Cactus-Yeast-Drosophila Model System. Edited by: Barker JSF, Starmer WT. Sydney: Academic Press; 1982:97-106

48. de Brito RA, Manfrin MH, Sene FM: Nested cladistic analysis of Brazilian populations of Drosophila serido. Mol Phylogenet Evol 2002, 22:131-143.

49. Etges WJ, Tripodi AD: Premating isolation is determined by larval rearing substrates in cactophilic Drosophila mojavensis. VIII. Mating success mediated by epicuticular hydrocarbons within and between isolated populations. J Evol Biol 2008, 21:1641-1652.

50. SAS-Institute: SAS/STAT 9.1.2. Cary, NC: SAS Institute, Inc. 2004.

51. Dyer RJ: GeneticStudio: a suite of programs for spatial analysis of genetic-marker data. Mol Ecol Res 2009, 9(1):110-113.

52. Veness C: Latitude/longitude spherical geodesy formulae \& scripts. 2002 [http://www.movable-type.co.uk/scripts/latlong.html].

53. Ruiz A, Ranz JM, Cáceres M, Segarra C, Navarro A, Barbadilla A: Chromosomal evolution and comparative gene mapping in the Drosophila repleta species group. Brazil J Genet 1997, 20(4):553-565.

54. Santos MH, Franco FF, Manfrin MH: The mitochondrial COI gene fails as DNA barcoding in the sibling species of Drosophila buzzatii cluster. Dros Inf Serv 2009, 92:101-106.

55. Tamura K, Dudley J, Nei M, Kumar S: MEGA4: Molecular Evolutionary Genetics Analysis (MEGA) software version 4.0. Mol Biol Evol 2007 24:1596-1599.

56. Swofford DL: PAUP*. Sunderland, MA: Sinauer; 42000

57. Maddison WP, Maddison DR: Mesquite: a modular system for evolutionary analysis. Version 2.6. 2009.

58. Durando CM, Baker RH, Etges WJ, Heed WB, Wasserman M, DeSalle R: Phylogenetic analysis of the repleta species group of the genus Drosophila using multiple sources of characters. Mol Phylogenet Evol 2000 16:296-307.

59. Ruiz A, Heed WB, Wasserman M: Evolution of the mojavensis cluster of cactophilic Drosophila with descriptions of two new species. $J$ Hered 1990, 81:30-42.

60. Losos JB: Uncertainty in the reconstruction of ancestral character states and limitations on the use of phylogenetic comparative methods. Anim Behav 1999, 58:1319-1324.

61. Martins EP, Hansen TF: Phylogenies and the comparative method: a general approach to incorporating phylogenetic information into the analysis of interspecific data. Am Nat 1997, 149(4):646-667.

62. Cunningham CW, Omland KE, Oakley TH: Reconstructing ancestral character states: a critical reappraisal. Trends Ecol Evol 1998, 13(9):361-366.

63. Swofford DL, Maddison WP: Reconstructing ancestral character states under Wagner parsimony. Math Biosci 1987, 87:199-229.

64. Maddison WP: Squared-change parsimony reconstructions of ancestral states for continuous-valued characters on a phylogenetic tree. Syst Zool 1991, 40:304-314

65. Martins EP, Garland T: Phylogenetic analysis of the correlated evolution of continuous characters: a simulation study. Evolution 1991, 45:534-557.

66. Moran AL: Egg size evolution in tropical American arcid bivalves: The comparative method and the fossil record. Evolution 2004, 58(12):2718-2733.

67. Laurin M: The evolution of body size, Cope's rule and the origin of amniotes. Syst Biol 2004, 53(4):594-622.

68. Abouheif $\mathrm{E}: \mathrm{A}$ method for testing the assumption of phylogenetic independence in comparative data. Evol Ecol Res 1999, 1:895-909.

69. Reeve J, Abouheif E: Phylogenetic Independence. Version 2.0. 2003.

70. Laurin M, Canoville A, Quilhac A: Use of paleontological and molecular data in supertrees for comparative studies: the example of lissamphibian femoral microanatomy. J Anat 2009, 215(2):110-123.

71. Benjamini $Y$, Hochberg $Y$ : Controlling the false discovery rate: a practical and powerful approach to multiple testing. J R Stat Soc B 1995, 57(1):289-300.

72. Heed WB, Mangan RL: Community ecology of the Sonoran desert Drosophila. In The genetics and biology of Drosophila. Volume 3e. Edited by: Ashburner M, Carson HL, Thompson JN. New York: Academic Press; 1986:311-345.

73. Etges WJ, Johnson WR, Duncan GA, Huckins G, Heed WB: Ecological genetics of cactophilic Drosophila. In Ecology of Sonoran Desert plants and 
plant communities. Edited by: Robichaux R. Tucson: University of Arizona Press; 1999:164-214.

74. Russo CAM, Takezaki N, Nei M: Molecular phylogeny and divergence times of Drosophilid species. Mol Biol Evol 1995, 12:391-404.

75. Morán T, Fontdevila A: Phylogeny and molecular evolution of the Drosophila hydei subgroup (Drosophila repleta group) inferred from the Xanthine dehydrogenase gene. Mol Phylogenet Evol 2005, 36:695-705.

76. Nelson DR: Methyl-branched lipids in insects. In Insect Lipids Chemistry, Biochemistry and Biology. Edited by: Stanley-Samuelson DW, Nelson DR. University of Nebraska Press; 1993:467.

77. Schal C, Sevala VI, Young HP, Bachmann JAS: Sites of synthesis and transport pathways of insect hydrocarbons: Cuticle and ovary as target tissues. Am Zool 1998, 38:382-393.

78. Gibbs AG: Waterproofing properties of cuticular lipids. Am Zool 1998, 38:471-482.

79. Gibbs A, Pomonis JG: Physical properties of insect cuticular hydrocarbons: the effects of chain length, methyl-branching and unsaturation. Comp Biochem Physiol 1995, 112:243-249.

80. Gibbs AG, Fukuzato F, Matzkin LM: Evolution of water conservation mechanisms in desert Drosophila. J Exp Biol 2003, 206:1183-1192.

81. Ishii K, Hirai Y, Katagiri C, Kimura MT: Sexual isolation and cuticular hydrocarbons in Drosophila elegans. Heredity 2001, 87:392-399.

82. Oguma $Y$, Nemoto T, Kuwahara Y: A sex pheromone study of a fruit-fly Drosophila virilis Sturtevant (Diptera: Drosophilidae): Additive effect of cuticular alkadienes to the major sex pheromone. Appl Entomol Zool 1992, 27:499-505.

83. Oguma $Y$, Nemoto $T$, Kuwahara $Y$ : (Z)-11-Pentacosene is the major sex pheromone component in Drosophila virilis. Chemoecology 1992, 3:60-64.

84. Shirangi TR, Dufour HD, Williams TM, Carroll SB: Rapid evolution of sex pheromone-producing enzyme expression in Drosophila. PLoS Biol 2009, 7(8):e1000168

85. Kwan L, Rundle HD: Adaptation to desiccation fails to generate pre- and postmating isolation in replicate Drosophila melanogaster laboratory populations. Evolution 2010, 64(3):710-723.

86. Dani FR, Jones GR, Destri S, Spencer SH, Turillazzi S: Deciphering the recognition signature within the cuticular chemical profile of paper wasps. Anim Behav 2001, 62(1):165-171.

87. Châline N, Sandoz J-C, Martin SJ, Ratnieks FLW, Jones GR: Learning and Discrimination of Individual Cuticular Hydrocarbons by Honeybees (Apis mellifera). Chem Senses 2005, 30(4):327-335.

88. Gleason JM, Ritchie MG: Evolution of courtship song and reproductive isolation in the Drosophila willistoni species complex: Do sexual signals diverge the most quickly? Evolution 1998, 52:1493-1500.

89. Carson HL: Sexual selection in populations: the facts require a change in the genetic definition of the species. In Evolutionary genetics: from molecules to morphology. Edited by: Singh RS, Krimbas C. New York: Cambridge University Press; 2000:495-512.

90. Wiens JJ: Widespread loss of sexually selected traits: how the peacock lost its spots. Trends Ecol Evol 2001, 16(9):517-523.

91. Greenfield MD: Signalers and receivers: mechanisms and evolution of arthropod communication. New York: Oxford Univ. Press; 2002.

92. Symonds MRE, Elgar MA: The mode of pheromone evolution: evidence from bark beetles. Proc R Soc Lond B Biol Sci 2004, 271(1541):839-846.

93. Symonds MRE, Wertheim B: The mode of evolution of aggregation pheromones in Drosophila species. J Evol Biol 2005, 18:1253-1263.

94. Page M, Nelson LJ, Blomquist GJ, Seybold SJ: Cuticular hydrocarbons as chemotaxonomic characters of pine engraver beetles (Ips spp.) in the grandicollis subgeneric group. J Chem Ecol 1997, 23(4):1053-1099.

95. Martin S, Drijfhout F: A review of ant cuticular hydrocarbons. J Chem Ecol 2009, 35:1151-1161.

96. Henry CS, Wells MLM, Simon CM: Convergent evolution of courtship songs among cryptic species of the carnea group of green lacewings (Neuroptera: Chrysopidae Chrysoperla). Evolution 1999, 53(4):1165-1179.

97. Omland KE, Lanyon SM: Reconstructing plumage evolution in Orioles (Icterus): Repeated convergence and reversal in patterns. Evolution 2000, 54(6):2119-2133.

98. Kusmierski R, Borgia $\mathrm{G}$, Uy A, Crozier RH: Labile evolution of display traits in bowerbirds indicates reduced effects of phylogenetic constraint. Proc R Soc Biol Sci Ser B 1997, 264(1380):307-313.

99. Price JJ, Lanyon SM: Reconstructing the evolution of complex bird song in the Oropendolas. Evolution 2002, 56(7):1514-1529.
100. Gleason JM, James RA, Wicker-Thomas C, Ritchie MG: Identification of quantitative trait loci function through analysis of multiple cuticular hydrocarbons differing between Drosophila simulans and Drosophila sechellia females. Heredity 2009, 103(5):416-424.

101. Wigglesworth VB: The source of lipids and polyphenols for the insect cuticle: the role of fat body, oenocytes and oenocytoids. Tissue Cell 1988, 20:919-932.

102. Balloux F: The worm in the fruit of the mitochondrial DNA tree. Heredity 2010, 104(5):419-420

103. Baimai V, Sene FM, Pereira MAQR: Heterochromatin and karyotypic differentiation of some Neotropical cactus breeding species of the Drosophila repleta species group. Genet Res 1983, 60:81-92.

104. Tosi D, Sene FM: Further studies on chromosomal variability in the complex taxon Drosophila serido (Diptera, Drosophilidae). Rev Bras Genet $1989,12: 729-745$

105. Silva AFG, Sene FM: Morphological geographic variability in Drosophila serido (Diptera, Drosophilidae). Rev Bras Entomol 1991, 35:455-468.

106. Benado M: Competitive release in the cactophilic fly, Drosophila venezolana. Ecotropicos 1989, 2:45-48.

107. Marín I, Ruiz A, Pla C, Fontdevila A: Reproductive relationships among ten species of the Drosophila repleta group from South America and the West Indies. Evolution 1993, 47(5):1616-1624.

108. Vilela CR: A revision of the Drosophila repleta species group (Diptera: Drosophilidae). Rev Bras Entomol 1983, 27:1-114.

doi:10.1186/1471-2148-11-179

Cite this article as: Oliveira et al: Variations on a theme: diversification of cuticular hydrocarbons in a clade of cactophilic Drosophila. BMC Evolutionary Biology 2011 11:179.

\section{Submit your next manuscript to BioMed Central and take full advantage of:}

- Convenient online submission

- Thorough peer review

- No space constraints or color figure charges

- Immediate publication on acceptance

- Inclusion in PubMed, CAS, Scopus and Google Scholar

- Research which is freely available for redistribution

Submit your manuscript at www.biomedcentral.com/submit
C Biomed Central 